\title{
1 Tandem structured spectrally selective coating layer of copper oxide \\ 2 nanowires combined with cobalt oxide nanoparticles
}

3

4

5 Jirapon Khamwannah ${ }^{1,3}$, Dongwon Chun ${ }^{1,3}$, Duyoung Choi ${ }^{1,3}$, Alireza Kargar ${ }^{1,3}$, Renkun Chen ${ }^{1,}$

$6 \quad 3$, Zhaowei $\mathrm{Liu}^{2}$, and Sungho Jin ${ }^{1,3, *}$

7

$8 \quad{ }^{1}$ Materials Science \& Engineering, ${ }^{2}$ Electrical \& Computer Engineering, and ${ }^{3}$ Mechanical and

9 Aerospace Engineering, University of California at San Diego, 9500 Gilman Dr., La Jolla, CA 92093, USA

${ }^{4}$ Mechanical Engineering, University of Nevada at Las Vegas, 4505 S. Maryland Pkwy., Las Vegas, NV 89154, USA

* Corresponding author : jin@ucsd.edu

\section{Abstract}

Increasing the light absorption across the wide solar spectrum has important implications for applications in solar-thermal and photovoltaic energy conversion. Here, we report novel tandem structures combing two different materials with complementary optical properties and microstructures: copper oxide $(\mathrm{CuO})$ nanowires $(\mathrm{NWs})$ and cobalt oxide $\left(\mathrm{Co}_{3} \mathrm{O}_{4}\right)$ nanoparticles (NPs). Copper oxide NWs of 100-200 nm in diameter and $5 \mu \mathrm{m}$ long are grown thermally on copper foil in air and cobalt oxide $\left(\mathrm{Ce}_{3} \mathrm{\Theta}_{4}\right)$ NPs of 100-200 nm in diameter are synthesized hydrothermally. Tandem structures of spectrally selective coating (SSC) layer are built with three different methods: spray-coating, dip-coating of cobalt oxide- $\mathrm{C}_{3} \mathrm{\Theta}_{4} \mathrm{NPs}$ into copper oxide NWs forest, and transferring of copper oxide NWs layer onto cobalt oxide NPs layer. The figure of merit (FOM) of light absorption is determined from optical reflectance measurements on each 
of the fabricated samples. The tandem-structured SSC layers fabricated from the spray-coating,

2 dip-coating and transferring methods exhibit figure of merit (FOM) values of 0.875, 0.892 and

30.886 , respectively, which are significantly higher than that of the starting copper oxide NWs

$4 \quad(\mathrm{FOM}=0.858)$ and cobalt oxide NPs $(\mathrm{FOM}=0.854)$. Our results demonstrate the efficacy of

5 using novel tandem structures for enhanced light absorption of solar spectrum, which will find

6 broad applications in solar energy conversion.

7

8 Keywords: tandem structure, spectrally selective coating (SSC) layer, copper oxide nanowires, 9 cobalt oxide nanoparticles, solar absorption, solar thermal.

\section{Introduction}

The Earth receives an enormous amount of incoming solar radiation generated by fusion reaction in the sun, which is expected to remain stable for the next 4 billion years $[1,2]$. Therefore, solar energy is the most plentiful resource for energy supply. Photovoltaic (PV) solar cells, concentrating solar power (CSP) systems, solar thermoelectric generators as well as photoelectrochemical water splitting systems harvest solar energy for electricity or fuel [3-8].

CSP system uses heliostat mirror arrays to concentrate sunlight to the spectrally selective coating (SSC) layer on the solar receiver structure (such as a corrosion-resistant Inconel alloy tube) to heat up a heat transfer fluid inside (e.g., a molten salt), which is then transported to create high-pressure steam and utilized to drive a steam-turbine-type heat engine to generate

22 electricity. The CSP system is already commercialized with a multi-gigawatt level power generations, with a fast industrial growth in progress, especially with a recent recognition of CSP's advantage of potentially inexpensive energy storage (e.g., by using molten salt reservoir),

25 which can be quite useful and beneficial for control of energy distribution in energy grid systems [4].

Among many approaches to increase the efficiency of solar-based energy conversion devices, nanowire (NW) structures have been used for enhanced light absorption and charge separation, such as demonstrated in Si micro-nanowires for PV solar cells [9-12] and copper oxide NWs for photoelectrochemical water splitting systems [13, 14]. For CSP type solar 
thermal applications, Si NWs is not suitable because the band gap of Si (1.12 eV at $300 \mathrm{~K}$ [15]) is not sufficiently low to absorb near-infrared (IR) sunlight spectrum and pure Si can be easily oxidized when exposed to air at high temperature. For instance, $\sim 45 \mathrm{~nm}$ of silicon oxide will grow on $\mathrm{Si}$ when it is annealed at $700{ }^{\circ} \mathrm{C}$ for $100 \mathrm{~h}$ under dry oxygen atmosphere [16] and $\mathrm{Si}$ nanoparticle has been reported to increase its weight by $\sim 15 \mathrm{wt} \%$ through the oxidation at $750{ }^{\circ} \mathrm{C}$ for $2 \mathrm{~h}$ in dry oxygen [17]. In this regard, copper Copper-oxide $(\mathrm{CuO})$ is a better candidate material in this regard-because it is already oxidized into a stable oxide form and should be resistant to oxidation in air. For highly efficient CSP system, it is desirable for the SSC layer to absorb as much sunlight as possible with high absorption and low sunlight reflectivity in the visible and near-IR spectrum range. The wavelength regime of interest for CSP solar energy absorption includes the visible spectrum range $(<\sim 700 \mathrm{~nm})$ and near IR spectrum range $(\sim 700$ $\mathrm{nm}-1.6 \mathrm{um})$. Based on our measurements, copper oxide NWs exhibit relatively high sunlight reflection characteristics in near-IR spectrum, even though the reflection in visible spectrum is quite low. Copper oxide $(\mathrm{CuO})$ has been reported to have band gap of 1.2-1.4 eV which corresponds to the absorption from the wavelength of 890-1030 nm [18-19]. This optical property of $\mathrm{CuO}$ results in high reflectance of near-IR spectrum longer than 890-1030 nm. Therefore, it is necessary to combine another near-IR absorbing material layer with copper oxide NWs structure, which could then enable efficient sunlight absorption over a broader spectrum range.

As a desirable material to absorb near-IR spectrum, semiconducting metal oxides with small band gap can be utilized. For example, one phase of cobalt oxide, $\mathrm{Co}_{3} \mathrm{O}_{4}$, has absorption bands at several spectrum ranges including 0.82-0.85 eV ( 1500 nm), 0.93-1.03 eV (1340-1200 $\mathrm{nm}), \quad 1.5-2.07 \mathrm{eV}(850-700 \mathrm{~nm})$ and 1.88-3.1 eV (660-400 nm) [20-24][17-21] which means $\mathrm{Co}_{3} \mathrm{O}_{4}$ can become a candidate to increase the absorption of near-IR spectrum when combined with copper oxide NWs structure. We have introduced a hybrid structure containing both $\mathrm{Co}_{3} \mathrm{O}_{4}$ and $\mathrm{Cu}$ oxide NWs so as to broaden the absorbed spectrum range of sunlight. Such a 'tandem structure' approach has also been used in PV solar cells to absorb different spectrum ranges using a combination of materials or different sized quantum dots having different band gaps [2527][22-24], however, such an approach has not been investigated much in the case of CSP solar absorber materials. 
In this work, new tandem structures of SSC layer having copper oxide NWs and cobalt

2 oxide $\left(\mathrm{Co}_{3} \mathrm{O}_{4}\right)$ NPs have been prepared by scalable spray-coating or dip-coating type processes.

3 Our results indicate that this tandem structure of SSC layers significantly increase the absorption

4 of sunlight, which is expected to improve the energy conversion efficiency of solar thermal

5 systems such as CSP and solar thermoelectric generation systems.

6

7 Materials and methods

8

Thermal growth of copper oxide nanowires

Thermal growth of copper oxide nanowires (NWs) was made by annealing copper foil in air atmosphere [13-14]. As a pretreatment procedure, the purchased copper foil (Alfa Aesar, $50 \mu \mathrm{m}$ thick) was cleaned with hexane, acetone, isopropyl alcohol and distilled water, followed by drying with air blowing. The copper foil was heated with a rate of $20{ }^{\circ} \mathrm{C} / \mathrm{min}$ up to $500{ }^{\circ} \mathrm{C}$ and held for $5 \mathrm{~h}$ under air atmosphere. After cooling down to room temperature, a dense array of copper oxide NWs was obtained on copper foil. The imagestructure of the copper oxide NWs was analyzedobserved by X ray diffraction analysis (XRD) and-scanning electron microscopy (SEM) and the crystal structure of nanowires was analyzed with X-ray diffraction analysis (XRD), transmission electron microscopy (TEM) and energy-dispersive X-ray spectroscopy (EDX) as shown in Figure 1(a), and-Figure 2(a), Figure 3 and Figure 4.

\section{Hydrothermal synthesis of cobalt oxide nanoparticles}

22 A two-step synthesis method was used to produce cobalt oxide $\left(\mathrm{Co}_{3} \mathrm{O}_{4}\right)$ nanoparticles (NPs), 23 with the first step of precipitation into cobalt hydroxide and the second step of hydrothermal 24 synthesis to make cobalt oxide NPs. The precursor cobalt chloride $\left(\mathrm{CoCl}_{2} \cdot 6 \mathrm{H}_{2} \mathrm{O}\right)$ was purchased 25 (Alfa Aesar) and dissolved in distilled water in concentration of 1.0 M. To induce a precipitation of $\mathrm{Co}(\mathrm{OH})_{2}, 10.0 \mathrm{M} \mathrm{NaOH}$ aqueous solution was added gradually until the $\mathrm{pH}$ of the mixed

27 solution reached 11.5. The mixed solution was placed inside a Teflon liner of high pressure steel container and subjected to a hydrothermal synthesis for $20 \mathrm{~h}$ at $150{ }^{\circ} \mathrm{C}$. 
After the synthesis, the remaining precursor solution and reaction byproducts were removed with repeated washing in distilled water followed by centrifuging, after which freezedrying for 1 day was employed to dry the cobalt oxide nanoparticles. The dried particles were annealed at $750{ }^{\circ} \mathrm{C}$ for $2 \mathrm{~h}$ to fully crystallize into $\mathrm{Co}_{3} \mathrm{O}_{4} \mathrm{NPs}$. The processed $\mathrm{Co}_{3} \mathrm{O}_{4} \mathrm{NPs}$ were composed of mainly particles having 100-200 nm in average size. The structure of the $\mathrm{Co}_{3} \mathrm{O}_{4}$ NPs was analyzed by XRD and SEM microscopy and XRD as shown in Figure 1(b) and Figure 2(b).

\section{Designs of SSC layers to increase optical absorption}

Based on the evaluation of optical reflectance of $\mathrm{CuO}$ NWs alone and that of $\mathrm{Co}_{3} \mathrm{O}_{4} \mathrm{NPs}$ alone (see Figure 6(a)Figure 4(a)), it is seen that copper oxide nanowires (NWs) can absorb a large amount of visible spectrum. By contrast, the coated layer of $\mathrm{Co}_{3} \mathrm{O}_{4}$ nanoparticles (NPs) exhibits a much higher optical reflectance in the visible range than $\mathrm{CuO}$ NWs, but shows an advantage of absorbing more near-IR spectrum than the $\mathrm{CuO}$ NWs. Therefore, a combined tandem structure of copper oxide NWs and cobalt oxide NPs was devised to take advantage of both materials unique characteristics and achieve higher absorption of sunlight in both near-IR and visible spectrum. The SEM micrograph of Figure 6(b)Figure 4(b) shows one example of such a combined tandem structure of $\mathrm{CuO} \mathrm{NWs}$ and $\mathrm{Co}_{3} \mathrm{O}_{4} \mathrm{NPs}$. This concept of tandem structure formation for optically improved SSC layer is more clearly illustrated by schematic diagrams of Figure 5Fig. 3.

According to Figure 5Figure 3, vertically aligned $\mathrm{CuO}$ NWs and spherical $\mathrm{Co}_{3} \mathrm{O}_{4} \mathrm{NPs}$ can be combined in two different configurations. One way is to coat the vertical $\mathrm{CuO} \mathrm{NWs}$ with cobalt oxide NPs by means of spray-coating, or dip-coating method which makes micro-cone type of structure formed with cobalt oxide NPs, as shown in the left side procedure of Figure 5Figure 3. Another way of tandem structure formation is to have the copper oxide NW layer itself separated from the copper foil substrate by wet-etching removal of $\mathrm{Cu}$, followed by attachment of it on top of micro-layer of cobalt oxide NPs pre-deposited on Inconel substrate surface, as represented by the right side procedure of Figure 5Figure 3. 


\section{Fabrication of tandem SSC layers}

2 Spectrally selective coating (SSC) layer of copper oxide nanowires (NWs) combined with cobalt 3 oxide $\left(\mathrm{Co}_{3} \mathrm{O}_{4}\right)$ nanoparticles (NPs), was fabricated with three different methods including spraycoating, dip-coating, and transferring.

For the preparation of coating solution for spray-coating of the synthesized cobalt oxide NPs, phenyl-methyl polysiloxane resin (purchased from Evonik (Germany, SILIKOPHEN P $80 / \mathrm{X})$ ) was utilized as a binder resin. After diluting to $6 \mathrm{wt} \%$ by adding a cosolvent of isobutanol/xylene $(1 / 3 \mathrm{v} / \mathrm{v}$ ratio) to the purchased resin solution, cobalt oxide NPs were then added to the diluted binder solution with a composition of 4:1 (w/w) (cobalt oxide: pheny-methyl polysiloxane). In the final coating solution, the concentration of total solid consisting of cobalt oxide and a binder became $18 \mathrm{wt} \%$. The nanoparticle dispersion was further improved by sonication followed by ball-mixing for 1 day. On the surface of copper oxide NWs (which are semi-vertically aligned on $\mathrm{Cu}$ foil surface), the final cobalt oxide NPs coating solution was spray-coated (Figure 3, left side schematics in Figure 5) after which the binder resin was cured at $250{ }^{\circ} \mathrm{C}$ for $1 \mathrm{~h}$ in air atmosphere.

Cobalt oxide solutions with different concentrations of $18 \mathrm{wt} \%$ and $6 \mathrm{wt} \%$ were used for the dip-coating of cobalt oxide NPs into the copper oxide NW structure. The cobalt oxide solution of $18 \mathrm{wt} \%$ prepared as described above was used for dip-coating into copper oxide NW structure with different dipping methods, including a continuous longer time dipping (10 min) without making the solution container to be vacuum state, and a dipping with 1 cycle of vacuum $(20 \mathrm{sec})$ and venting. For a diluted coating solution with a solid concentration of $6 \mathrm{wt} \%$, the previous $18 \mathrm{wt} \%$ solution was diluted by a factor of 3 by adding isobutanol/xylene $(1 / 3 \mathrm{v} / \mathrm{v})$. With this diluted cobalt oxide solution (6 wt\%), copper oxide NW structure was dip-coated using 1 cycle of vacuum/venting and 3 cycles of vacuum/venting procedure. For all these dip-coating procedures, the drying and curing procedure was carried out at $250^{\circ} \mathrm{C}$ for $1 \mathrm{~h}$ in air environment.

For an alternative tandem structure by transferring of copper oxide NW layer and placing it on top of cobalt oxide NP layer (Figure 3, right side schematics in Figure 5), the copper oxide NWs grown thermally on copper foil was separated from the copper foil by wet-etching removal of remaining $\mathrm{Cu}$ in a mixed aqueous solution of 3.0 M iron chloride solution and 37\% 
1 hydrochloric acid solution $(25 / 1 \mathrm{w} / \mathrm{w})$. Before transferring, thin binder resin layer of phenyl-

2 methyl polysiloxane was coated on cobalt oxide NP layer $(30 \mu \mathrm{m})$ formed on Inconel alloy

3 (Type 625) substrate by spray-coating at $40 \mathrm{psi}$ pressure, using the cobalt oxide NP solution with

$418 \mathrm{wt} \%$ concentration. The separated copper oxide NW layer was transferred onto the binder

5 resin layer, followed by drying and curing at $250{ }^{\circ} \mathrm{C}$ for $1 \mathrm{~h}$ in air atmosphere.

7 Optical reflectance measurement and figure of merit (FOM) evaluation

8 Visible/infrared (IR) reflectance of different types of SSC layers was measured, using a home-

9 made reflectance measurement system consisting of an integration sphere (4" LabSphere ${ }^{\circledR}$, Spectraflect ${ }^{\circledR}$ coated) assembled with an Andor ${ }^{\circledR}$ Shamrock 303 i spectrometer equipped with $\mathrm{Si}$ and InGaAs-based detectors. The optical reflectance was measured with incidence angle of $12.5^{\circ}$ in the spectrum range of 400-2000 $\mathrm{nm}$ for SSC layers at room temperature. Merit (FOM) value was evaluated for various SSC layers including the tandem structured SSC

15 layers. The figure of merit (FOM) is defined as follows (Equation 1).

$$
F=\frac{\int_{0}^{\infty}(1-R(\lambda)) I(\lambda) d \lambda-\frac{1}{C}\left[\int_{0}^{\infty}(1-R(\lambda)) B(\lambda, T) d \lambda\right]}{\int_{0}^{\infty} I(\lambda) d \lambda}
$$

where $R(\lambda)$ is the spectral reflectivity, $I(\lambda)$ is the spectral solar irradiance per square meter as defined by the reference solar spectral irradiation(ASTM G173), B( $\lambda, T)$ is the spectral thermal emission of a black body at $\mathrm{t}$ emperature $\mathrm{T}$, and $\mathrm{C}$ i $\mathrm{s}$ the conc entration ratio. For la rge concentration ratio of $\mathrm{m}$ irror-focused s unlight such a s s olar pow er tower type C SP ge nerator systems, the optical absorption (related to optical reflectance properties) is the dominant factor.

\section{XRD, TEM, EDX and SEM analysis}

X-ray diffraction (XRD) analysis was carried out to investigate the crystal structure of copper 4 oxide nanowires (NWs) and cobalt oxide nanoparticles (NPs). Copper oxide NWs were separated from copper foil by scraping off with a razor blade. Crystal structures of copper oxide 
NWs and cobalt oxide NPs were characterized by Bruker D2 Phaser XRD with $\mathrm{Cu} \mathrm{K}_{\alpha}(\lambda=0.154$

$\mathrm{nm}$ ) as the radiation source. The scanning of $2 \theta$ angle (degree) was made in the range of $20^{\circ}-70$ ${ }^{\mathrm{o}}$ with a scanning rate of $1.0 \mathrm{deg} / \mathrm{min}$.

In order to analyze more precisely the crystal structure of copper oxide nanowires, a single copper oxide nanowire was analyzed with transmission electron microscope (TEM) (FEI Tecnai F20 G ${ }^{2}$ ) operated at the acceleration voltage of $200 \mathrm{kV}$ in bright field (BF) mode and high resolution (HR) mode, followed by fast Fourier transform (FFT) analysis to confirm the crystal structure of the nanowire.

The copper oxide phases existing at different positions in the cross-sectional area of copper oxide NW structure were analyzed using energy-dispersive X-ray spectroscopy (EDX) installed with scanningSeanning electron microscopy (SEM) (Oxford), with an acceleration energyvoltage of $10 \mathrm{kV}$.KeV to observe The structures of copper oxide NWs, cobalt oxide NPs, and the combined tandem structured SSC layers were imaged by SEM.

\section{Results and discussion}

\section{Characterization of copper oxide NWs and cobalt oxide NPs}

The XRD analysis indicates thateenfirms that the scraped-off copper oxide nanowires (NWs) have-two crystal phases including $\mathrm{CuO}$ phase and $\mathrm{Cu}_{2} \mathrm{O}$ phase (* mark) as shown in Figure 2(a)1(a). For $\mathrm{CuO}$ crystal structure, two main planes of (111) and (111) are observed at $2 \theta=$ $35.6^{\circ}$ and $38.7^{\circ}$, respectively in end-centered monoclinic system [2825]. For $\mathrm{Cu}_{2} \mathrm{O}$ crystal structure there are three planes including (110), (111) and (200) at $2 \theta=29.5^{\circ}, 36.3^{\circ}$, and $42.3^{\circ}$, respectively in primitive cubic system [2926]. $\mathrm{CuO}$ phase can come from the crystal structure of nanowires and Most of the $\mathrm{Cu}_{2} \mathrm{O}$ phase in XRD analysis can-may originate from the material in the-flat copper oxide bottom layer at the bottom of from which the copper oxide NWs grow. Because the some chunks of bottom layer can be taken out together with nanowires during the strong scraping during the razor blade removal process. 
In addition to the previous research on $\mathrm{CuO}$ NWs [13], our TEM and EDX analysis also confirm that the copper oxide nanowire is composed of only $\mathrm{CuO}$ crystal phase with band gap of 1.2-1.4 eV while the bottom layer copper oxide (from which the $\mathrm{CuO}$ nanowires grow) contains $\mathrm{CuO}$ in the upper portion of the layer while some $\mathrm{Cu}_{2} \mathrm{O}$ phase is present in the lower part of the

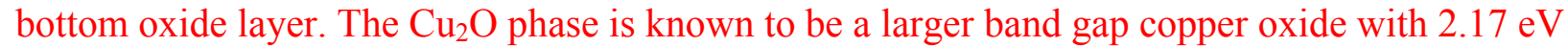
[18-19]. the color of nanowires looks black but the bottom layer from which nanowires grow is not as black, i.e., grayish color, which means the bottom oxide layer is composed of $\mathrm{Cu}_{2} \mathrm{O}$ having a larger band gap of $2.17 \mathrm{eV}$ [27]. With this large band gap, $\mathrm{Cu}_{2} \mathrm{O}$ absorbs less visible spectrum than $\mathrm{CuO}$ having a smaller band gap of $-1.4 \mathrm{eV}$ and hence less black in color and electrically less conductive [27-28]. The crystal structure of a single copper oxide nanowire is shown in the inset of the TEM image in Figure 3(a). The FFT pattern in Figure 3(b) obtained for all area of the nanowire in Figure 3(a) shows that the copper oxide nanowire consists of only $\mathrm{CuO}$ phase containing (101), (110), (111), (202), (202), (022) and (204) plane which corresponds to lattice plane spacing of $3.138 \AA, 2.739 \AA, 2.356 \AA, 1.885 \AA, 1.570 \AA, 1.425 \AA$ and $1.195 \AA$, respectively. The cross-sectional SEM image of CuO NW layer obtained by tilting $90^{\circ}$ was analyzed by EDX analysis at three points (a: nanowire at $2 \mu \mathrm{m}$ above the nanowire bottom surface, b: $1.5 \mu \mathrm{m}$ underneath the nanowire bottom surface (within the bottom copper oxide layer), and c: $8 \mu \mathrm{m}$ underneath the nanowire bottom surface) as exhibited in Figure 4. This EDX analysis at point a on nanowires indicates that the composition of overall nanowires is $1 / 1(\mathrm{Cu} / \mathrm{O})$ in atomic ratio which is in accordance with $\mathrm{CuO}$ phase as identified by TEM and FFT in Figure 3. The first point beneath nanowire's bottom surface (point $\mathbf{b}$ ) is confirmed to be composed of $\sim 1 / 1(\mathrm{Cu} / \mathrm{O})$ in atomic ratio corresponding to $\mathrm{CuO}$ phase, while the second point beneath the nanowire bottom surface (point c) shows $\sim 2 / 1(\mathrm{Cu} / \mathrm{O})$ in atomic ratio matching with $\mathrm{Cu}_{2} \mathrm{O}$ phase.

The nanowire layer (above 5 um thickness) is all made of $\mathrm{CuO}$ phase as identified by TEM. The upper portion of the oxide layer (from which the $\mathrm{CuO}$ nanowires grow) is $\sim 5$ um thick and also $\mathrm{CuO}$ phase as identified by EDX analysis. The lower portion of the bottom oxide layer contains some $\mathrm{Cu}_{2} \mathrm{O}$. Therefore, the optical reflectance behavior is mostly dominated by the $\mathrm{CuO}$ phase which is located at outermost two layers having total thickness of above $10 \mu \mathrm{m}$. During CSP operation at high temperature, it is likely that the $\mathrm{Cu}_{2} \mathrm{O}$ phase will eventually oxidize further 
to become $\mathrm{CuO}$, which is considered to be a beneficial reaction. For study of the stability of $\mathrm{CuO}$

2 phase at high temperature, the copper oxide nanowire layer was annealed at $500{ }^{\circ} \mathrm{C}$ for $10 \mathrm{~h}$ under air atmosphere and the overall atomic composition of $\mathrm{Cu} / \mathrm{O}$ was measured with $\mathrm{EDX}$ as

4 shown in Figure $\mathrm{S} 1$. The atomic composition of $\mathrm{CuO}$ in nanowires and in the upper portion of

5 the oxide bottom layer are stable enough to maintain $\sim 1 / 1$ ratio of $\mathrm{Cu} / \mathrm{O}$, which implies that the

6 formed $\mathrm{CuO}$ phase can be expected to retain the stable crystal structure and optical properties

7 during CSP operation.

Figure 2(b)1(b) shows XRD analysis of cobalt oxide nanoparticles (NPs) annealed at 750

${ }^{\circ} \mathrm{C}$ for $2 \mathrm{~h}$ in air. This analysis confirms that the hydrothermally synthesized cobalt oxide NPs are $\mathrm{Co}_{3} \mathrm{O}_{4}$ phase which has a main plane of (311) at $2 \theta=36.2^{\circ}$ in face-centered cubic system [3029].

The SEM image in Figure 1(a)Z(a) shows that the copper oxide NWs are longer than 5 $\mu \mathrm{m}$ in length and have 100-200 $\mathrm{nm}$ in diameter as can be seen more clearly in an inset image in Figure 1(a)Z(a). The spacing between adjacent nanowires appears to be roughly $500 \mathrm{~nm}$ to $2 \mathrm{um}$. The aspect ratio of nanowires is higher than $\sim 25$, which is believed to be beneficial for higher absorption efficiency due to light trapping effect [9-12]. The SEM image in Figure 1(b)z(b) exhibits that cobalt oxide NPs annealed at $750{ }^{\circ} \mathrm{C}$ for $2 \mathrm{~h}$ have mainly $100-200 \mathrm{~nm}$ in particle size, although some particles have a diameter as small as $50 \mathrm{~nm}$.

\section{Tandem structured SSC layer by spray-coating}

Tandem structure of solar absorbers can be fabricated with copper oxide nanowires (NWs) coated with the solution of cobalt oxide nanoparticles (NPs) by means of either spray-coating or dip-coating with the aforementioned concept explained in the left side procedure of Figure 53. Figure 1(a)2(a). Due to the vertically aligned nanowire structure of copper oxide, the cobalt 25 oxide solution, even with nanoparticle size, is difficult to uniformly penetrate all the way down to the bottom of nanowires through their interspace gap regions. Therefore, a micro-ball type of

27 cobalt oxide structure with a partial penetration into copper oxide NWs is formed when spray28 coating is carried out, as shown in Figure 6(b)-4(b). Even though the cobalt oxide NPs are not 
infiltrated into the bottom of the $\mathrm{CuO}$ nanowire array, the optical reflectance data in Figure 6(a) 4(a) shows that this type of tandem structure decreases near-IR reflectance due to the absorption of near-IR by $\mathrm{Co}_{3} \mathrm{O}_{4}$ NPs. The reflectance of visible light spectrum increases slightly compared to the copper oxide NWs only structure due to the addition of $\mathrm{someCo}_{3} \mathrm{O}_{4} \mathrm{NPs}$. The Figure of Merit (FOM) value increases a little from 0.864 to 0.875 when the copper oxide NWs is hybridized into a tandem structure with the addition of cobalt oxide NPs by spray-coating because the overall absorbed solar energy is larger in cobalt oxide NPs-sprayed copper oxide NWs due to the more substantial reduction of reflectance in the near-IR spectrum range relatively to the increment of the reflectance in the visible spectrum range.

\section{Tandem structured SSC layer by dip-coating}

Comparison of optical reflectance and FOM among different SSC layers, shown in Figure 7(a) $5(\mathrm{a})$, indicates that the optical reflectance properties are sensitive to the SSC layer structures and how they are produced. As compared to the rapid spray-coated structures, a slower process of dip-coating allows the cobalt oxide nanoparticles (NPs) to penetrate deeper into the spaces between copper oxide nanowires (NWs) having a relatively small spacing of $\sim 500 \mathrm{~nm}$ to $2 \mathrm{um}$ between adjacent nanowires. In addition, cobalt oxide NPs can also be entangled with copper oxide NWs, which may enable the formation of multi-scaled structures composed of the combination of microscale and nanoscale structures of nanowires and nanoparticles, as observed in Figure 7(c-1)-(d-2) $5(\mathrm{c} 1)(\mathrm{d} 2)$. The presence of some pore structures may also contribute to enhanced sunlight absorption. In order to make cobalt oxide NPs to infiltrate into copper oxide NW structures more efficiently, a cycle of vacuum suction/venting process is-was devised for the dip-coating process. The vacuum is was not a high vacuum but a typical, mechanical pump type of low vacuum was sufficient. The vacuum process extracts and removes most of entrapped air from copper oxide NWs structure, and this process causes the cobalt oxide NPsnanoparticles in solution to be sucked into the spaces that the air pocket previously occupied. Subsequent venting step allows the air to come in which generates such a large pressure difference between vacuum state and atmospheric pressure that cobalt oxide NP solution is pushed and driven into the interspace of aligned copper oxide NWs. Repeated vacuum/vent processes further improves the 
1 formation of tandem mixed structure and the sunlight absorption and the FOM properties are accordingly also improved as will be discussed later.

It is seen that without using the vacuum/venting process, the cobalt oxide NPs hardly get into the inter-nanowire spacing, as can be seen in Figure 7(b) $5(\mathrm{~b})$, but instead cover up the surface of the $\mathrm{CuO}$ nanowire structure as an almost continuous particle layer. Copper oxide NWs are rarely seen to protrude out of the cobalt oxide NP layer, except a few NWs which has very little affect on optical properties of SSC layers. As expected, the optical reflectance data of this monotonous structure shows a similar reflectance behavior to that of the SSC layer fabricated with cobalt oxide NPs only (Figure 7(a)-5(a)) and the FOM value of this structure is only 0.842 which is not high enough to absorb sufficient solar energy. This dip-coated sample without using vac./venting procedure produces a structure covered mostly with $\mathrm{Co}_{3} \mathrm{O}_{4}$ particles, with very few number of $\mathrm{CuO}$ nanowires protruding (Fig. 7(b)), so it is essentially $\mathrm{Co}_{3} \mathrm{O}_{4}$ particle surface. The spray-coating method to produce the $\mathrm{Co}_{3} \mathrm{O}_{4}$ particle $\mathrm{SSC}$ layer tends to have a high porosity and roughness as represented in Figure S2. Therefore, the $\mathrm{Co}_{3} \mathrm{O}_{4}$ layer of Figure S2 produces a slightly lower reflectance in the visible spectrum range.

The vacuum/venting process was utilized to make further advanced dip-coating structures with the concentrated solution of $18 \mathrm{wt} \%$. After placing the copper oxide NW sample into cobalt oxide NP solution, the vacuum is made for $20 \mathrm{sec}$ followed by a fast venting process with air, which may cause some interesting mechanical disturbance on the coating structure. As shown in Figure 7(c-1) and (c-2)-5(c-1) and (c-2), copper oxide NWs and cobalt oxide NPs form combined complex structures where copper oxide NWs are entangled with themselves coated with cobalt oxide NPs. In more details, a top side of this sample displays a spire-like roof layer of cobalt oxide NPs in Figure 7(c-1)-5(c-1) whose inset image shows the bottom surface coated with cobalt oxide NPs at interspaces between the copper oxide NWs. The tilted images including a magnified inset image in Figure 7(c-2)5(c-2) exhibit the entangled tripod-like structure of copper oxide NWs mixed with cobalt oxide NPs. Figure 7(a)-5(a) demonstrates that this 3dimensionally entangled tripod-like structure can decrease the reflectance in both visible and near-IR spectrum regime and obtain a higher FOM value of $0.876-0.8762$, compared to the sample made by a continuous dipping (Figure 7(b) $5(b)$ ). 
To better control the degree of entangling of copper oxide NWs and agglomeration of cobalt oxide NPs, the dip-coating solution was diluted to $6 \mathrm{wt} \%$, that is, $1 / 3$ of initial concentration, as the third approach. This third dip-coating method also uses the procedure of vacuum/venting, but due to the reduced solid concentration of nanoparticles and the binder resin, the insertion of the nanoparticles into the nanowire spacing gets easier. From the top view surface image (Figure 7(d-1)-5(d-1)) and a tilted view (Figure 7(d-2) $5(\mathrm{~d}-2)$ ), the occupied area by a spire-like top layer of cobalt oxide NPs is diminished (Figure 7(d-1)-5(d-1)) and micro-cone structure of cobalt oxide NPs is formed (see the inset of Figure 7(d-2) $5(\mathrm{~d}-2)$ ) instead of the tripod-like structure observed in Figure 7(c-2)-5(c-2). The dip-coating with a diluted solution of $6 \mathrm{wt} \%$ essentially maintains the nanowire structure of copper oxide after the dip-coating of cobalt oxide NPs so that a more or less uniform multi-scaled micro-nano structure can be made, which can be more effective in absorbing sunlight in both visible spectrum and near-IR spectrum.

Optical reflectance measurements in Figure 7(a)-5(a) shows that this multi-scaled tandem structure (Figure 7(d-1) and (d-2) 5(d-1) and (d-2)) coated with the diluted solution of 6 wt $\%$ exhibits much lower reflectance in visible spectrum and similarly reduced reflectance in near-IR spectrum range, compared to the entangled tripod-like structure (Figure 7(c-1) and (c-2)-5(c-1) and (c 2) made of cobalt oxide solution with higher concentration of $18 \mathrm{wt} \%$. The FOM value of this structure increases up to $0.892-0.8922$ which is much higher than the structure of Figure 7(c-1) and (c-2)-5(c-1) and (c-2). The lower reflectance in visible spectrum results from the wellpreserved nanowire structure of copper oxide and the similarly low reflectance of near-IR (1.0$1.55 \mu \mathrm{m})$ is attributed to the cone-type of microstructure of cobalt oxide NPs as well as the layer of cobalt oxide NPs coated on the bottom of copper oxide NWs as can be seen in the inset of Figure $7(\mathrm{~d}-1) 5(\mathrm{~d}-1)$. In the spectrum ranging from $1.55 \mu \mathrm{m}$ to $2.0 \mu \mathrm{m}$, the dip-coated layer with $6 \mathrm{wt} \%$ solution shows a steeper increase of reflectance than that with $18 \mathrm{wt} \%$ solution. The diluted $6 \mathrm{wt} \% \mathrm{Co}_{3} \mathrm{O}_{4}$ particles layer has less amount of $\mathrm{Co}_{3} \mathrm{O}_{4}$ than the $18 \mathrm{wt} \% \mathrm{Co}_{3} \mathrm{O}_{4}$ layer. It can be recognized that $\mathrm{Co}_{3} \mathrm{O}_{4}$ particles layer reflects less IR spectrum ranging from $1.0 \mu \mathrm{m}$ to 2.0 $\mu \mathrm{m}$ than $\mathrm{CuO}$ nanowires layer as can be compared in Figure 7(a). Lower concentration of $\mathrm{Co}_{3} \mathrm{O}_{4}$ particles can make thinner layer of $\mathrm{Co}_{3} \mathrm{O}_{4}$ particles and will result in less absorption which enable the SSC layer to have higher reflectance in IR spectrum compared to SSC layer coated with an $18 \mathrm{wt} \%$ solution (brown-colored graph in Figure 7(a)). What is interesting is that the 
reflectance of this structure (Figure $5(\mathrm{~d}-1)$ and $(\mathrm{d}-2))$ begins to increase steeply from the wavelength of $1.55 \mu \mathrm{m}$ to mid-IR direction. This behavior of reflectance increasing steeply from 1.55 um have cut-off wavelength around $1.55 \mu \mathrm{m}$ in order to reduce the emission loss of infrared spectrum. For instance, in the parabolic trough type concentrated solar power systems, the cutoff wavelength of $1.5 \mathrm{um}$ is helpful to increase FOM value by diminishing the amount of IR emission at $700^{\circ} \mathrm{C}[4]$. cycles of vacuum/venting by which more cobalt oxide NP material is pushed into the $\mathrm{CuO}$ NW structure so that an increased amount of cobalt oxide layer is expected to be deposited onto the bottom of $\mathrm{CuO}$ NW structure. The inset image of Figure 8(a)6(a) shows that the bottom of copper oxide NWs is covered with cobalt oxide NPs. Repeated vacuum/vent processes further improves the formation of tandem mixed structure with more cobalt oxide NPs deposited, with the sunlight absorption and the FOM properties accordingly improved. For example, 3 cycles of vacuum/venting process for dip-coating with the diluted solution of $6 \mathrm{wt} \%$ forms a somewhat larger area of a spire-like roof layer of cobalt oxide NPs (Figure 8(a)6(a)), compared to the structure made with just 1 cycle of vacuum/venting procedure (Figure $7(d-1) 5(d-1))$. From tilted images in Figure 8(b) 6(b), it can be observed that cobalt oxide NPs form micro-cone structure similar to the structure in the inset image of Figure $7(d-2)-5(d-2)$.

Optical reflectance measurement in Figure 97 indicates that the 3 cycle procedure slightly increases the reflectance of visible spectrum but noticeably decreases the reflectance of near-IR

22 as well as short wavelength IR spectrum. The small increase of reflectance in the visible spectrum results from the diminished nanowire structure of copper oxide caused by the addition of more nanoparticles and wider spire-like roof area of cobalt oxide NPs. The thicker cobalt oxide layer which can be expected by 3 repetition cycles absorbs a larger amount of sunlight near-IR spectrum $(1.6-2.0 \mu \mathrm{m})$ to result in the decreased reflectance in that wavelength regime. In the near-IR spectrum range, shorter near-IR $(0.8-1.6 \mu \mathrm{m})$ is more important to a solar absorber due to its higher energy than longer near-IR (above $1.6 \mu \mathrm{m}$ ). The SSC layer made by 3 cycles of vacuum/vent processing has FOM value of 0.891 which is very similar to that (0.892) of SSC layer by 1 cycle dip-coating. 
For a contrast experiment, a SSC layer was fabricated using the mixture solution (1/1 w/w) of $\mathrm{Co}_{3} \mathrm{O}_{4}$ particles and $\mathrm{CuO}$ nanowires which were scraped off from the copper foil. Using the same condition and ball-mixing procedure as the previous $\mathrm{Co}_{3} \mathrm{O}_{4}$ layer, the mixture solution was spray-coated on Inconel substrate and the reflectance of the sample was measured. Figure S3 indicates that the reflectance of the mixture sample is much higher in all spectrum range than the dip-coated SSC layer made with $6 \mathrm{wt} \%$ and vac./venting procedure. One possible reason for such a behavior is that the nanowires can be inadvertently shortened much during the ball-mixing process, thus the SSC layer has no structure advantage on entrapping sunlight, compared to SSC layer of vertically standing nanowires.

Tandem structured SSC layer by transferring of copper oxide NW layer

Copper oxide nanowire (NW) layer separated from $\mathrm{Cu}$ foil is composed of a horizontally configured copper oxide flat layer (1-2 $\mu \mathrm{m}$ thick) at the bottom from which copper oxide NWs have grown, as indicated in Figure 10(a) $8($ a). Figure 10(b) $-8(b)$ represents the final attached structure consisting of copper oxide NWs layer / polysiloxane binder resin layer / cobalt oxide NPs layer. It is expected that pure copper oxide NWs layer without cobalt oxide NPs is able to absorb more visible spectrum while the cobalt oxide NPs layer under copper oxide NW layer can absorb the near-IR spectrum transmitted through the copper oxide NW layer positioned above the nanoparticle layer, as explained in the aforementioned concept section (Figure 5).

The reflectance of visible spectrum is similarly as low as the pure copper oxide NW sample, but the reflectance of near-IR spectrum is not decreased as low as pure cobalt oxide

22 layers, as shown in Figure 119. The data in Figure 11-9 indicates that the reflectance value in the 23 shorter near-IR spectrum for the SSC layer fabricated by transferring the $\mathrm{CuO}$ NW layer is 24 higher than that for the SSC layer of pure cobalt oxide NPs and lower than that for the SSC layer 25 of pure copper oxide NWs, as well as SSC layer made by the spray-coating. Copper oxide NWs may reflect near-IR spectrum partially before it is transmitted to the bottom layer of $\mathrm{Co}_{3} \mathrm{O}_{4} \mathrm{NPs}_{\text {. }}$

27 Table 1 shows FOM values of the representative SSC layers including SSC layer fabricated by the transfer method. The tandem SSC layer by transferring has FOM value of 0.886 which is 
much higher than that of pure copper oxide NWs, pure cobalt oxide NPs and spray-coated SSC

2 layers, but lower than that of efficiently dip-coated SSC layer.

\section{Conclusion}

5 Tandem-structured spectrally selective coating (SSC) layer was newly devised with novel and

6 scalable methods to increase the absorption efficiency of solar spectrum. This new SSC layer

7 structure is simultaneously utilizing the thermally grown copper oxide NWs and the

8 hydrothermally synthesized cobalt oxide NPs. The tandem-structured SSC layer consists of a

9 multi-scaled combination of copper oxide nanowire (NW) layer having a good visible light

10 absorbing material and structure, together with wet-coated microstructure of cobalt oxide

11 nanoparticles (NPs) having a good near-IR absorbing characteristics. Various novel structured

12 SSC layers were built with 3 different fabrication methods including the spray-coating,

$13 \mathrm{vacuum} /$ vent processed advanced dip-coating of cobalt oxide NPs into copper oxide NWs forest,

14 and the transferring of copper oxide NWs layer onto cobalt oxide layer. The tandem-structured

15 SSC layers exhibited superior light absorbing properties in the visible and near-IR spectrum

16 range, with much higher figure of merit (FOM) values close to $\sim 0.90$. These tandem structures

17 and fabrication procedures to achieve higher and wider absorption of solar spectrum can be

18 highly useful for enhanced solar absorption in the field of solar energy conversion systems such

19 as concentrated solar thermoelectric generators and concentrating solar power systems.

\section{Acknowledgement}

22 The support of this research by Department of Energy through DOE SunShot Project (DE-

23 EE0005802) is acknowledged. 


\section{References}

[1] G. Brumfiel, Nature 436 (2005) 318-320.

[2] J. Beer, W. Mende, R. Stellmacher, Quaternary Science Reviews 19 (2000) 403-415.

[3] D. E. Carlson, C. R. Wronski, Appl. Phys. Lett. 28 (1976) 671-673.

[4] J. Moon, D. Lu, B. VanSaders, T. K. Kim, S. D. Kong, S. Jin, R. Chen, Z. Liu, Nano Energy 8 (2014) 238-246.

[5] D. Kraemer, B. Poudel, H.-P. Feng, J. C. Caylor, B. Yu, X. Yan, Y. Ma, X. Wang, D. Wang, A. Muto, K. McEnaney, M. Chiesa, Z. Ren, G. Chen, Nature Materials 10 (2011) 532-538.

[6] L. L. Baranowski, G. J. Snyder, E. S. Toberer, Energy Environ. Sci. 5 (2012) 9055-9067. [7] A. Fujishima, K. Honda, Nature 238 (1972) 37-38.

[8] M. Green, K. Emery, Y. Hishikawa, W. Warta, E. Dunlop, Prog. Photovolt: Res. Appl. 20 (2012) 12-20.

[9] K. Peng, Y. Xu, Y. Wu, Y. Yan, S.-T. Lee, J. Zhu, Small 1 (2005) 1062-1067.

[10] L. Tsakalakos, a J. Balch, J. Fronheiser, B. A. Korevaar, O. Sulima, J. Rand, Appl. Phys. Lett. 91 (2007) 233117-1-233117-3.

[11] M. D. Kelzenberg, S. W. Boettcher, J. A. Petykiewicz, D. B. Turner-Evans, M. C. Putnam, E. L. Warren, J. M. Spurgeon, R. M. Briggs, N. S. Lewis, H. A. Atwater, Nature Materials 9 (2010) 239-244.

[12] J. Zhu, Y. Cui, Nature Materials 9 (2010) 183-184.

[13] X. Jiang, T. Herricks, Y. Xia, Nano Lett. 2 (2002) 1333-1338.

[14] A. Kargar, Y. Jing, S. J. Kim, C. T. Riley, X. Pan, D. Wang, ACS Nano 7 (2013)1111211120 .

[15] W. H. Strehlow, E. L. Cook, J. Phys. Chem. Ref. Data 2 (1973) 163-199.

[16] B. E. Deal, A. S. Grove, J. Appl. Phys. 36 (1965) 3770-3778.

[17] T. K. Kim, J. Moon, B. VanSaders, D. Chun, C. J. Gardner, J.-Y. Jung, G. Wang, R. Chen, Z. Liu, Y. Qiao, S. Jin, Nano Energy 9 (2014) 32-40.

[18] J. Ghijsen, L. H. Tjeng, J. van Elp, H. Eskes, J. Westerink, G. A. Sawatzky, Phys. Rev. B 38 (1988) 11322-11330.

[19] F. P. Koffyberg, F. A. Benko, J. Appl. Phys. 53 (1982) 1173-1177.

[2017] J. G. Cook, M. P. Van Der Meer, Thin Solid Films 144 (1986) 165-176. 
1 [2118] P. NkengNKeng, G. Poillerat, J. F. Koenig, P. Chartier, B. Lefez, J. Lopitaux, M. Lenglet,

2 J. Electrochem. Soc. 142 (1995) 1777-1783.

3 [2219] P. Ruzakowski Athey, F. K. Urban III, M. F. Tabet, W. A. McGahan, J. Vac. Sci.

4 Technol. A14 (1996) 685-692.

5 [23ze] C.-S. Cheng, M. Serizawa, H. Sakata, T. Hirayama, Mater. Chem. Phys. 53 (1998) 225-

6230.

7 [2421] D. Barreca, C. Massignan, S. Daolio, M. Fabrizio, C. Piccirillo, L. Armelao, E. Tondello,

8 Chem. Mater. 13 (2001) 588-593.

9 [25z2] H. Keppner, J. Meier, P. Torres, D. Fischer, A. Shah, Appl. Phys. A 69 (1999) 169-177.

10 [26z3] G. Conibeer, M. Green, E.-C. Cho, D. König, Y.-H. Cho, T. Fangsuwannarak, G.

11 Scardera, E. Pink, Y. Huang, T. Puzzer, S. Huang, D. Song, C. Flynn, S. Park, X. Hao, D.

12 Mansfield, Thin Solid Films 516 (2008) 6748-6756.

13 [2724] K. A. Bertness, S. R. Kurtz, D. J. Friedman, A. E. Kibbler, C. Kramer, J. M. Olson, 65

14 (1994) 989-991.

15 [2825] S. Asbrink, A. Waskowska, J. Phys.: Condens. Matter. 3 (1991) 8173-8180.

16 [2926] R. Restori, D. Schwarzenbach, Acta Cryst. B42 (1986) 201-208.

17 [27] J. Ghijsen, L. H. Tjeng, J. van Elp, H. Eskes, J. Westerink, G. A. Sawatzky, Phys. Rev. B 38

18 (1988) $11322-11330$.

19

[28] F. P. Koffyerg, F. A. Benke, J. A ppl. Phys. 53 (1982) 11731177.

20 [3029] J.P. Picard, G. Baud, J. P. Besse, R. Chevalier, J. Less-Common Met. 75 (1980) 99-104.

21

22

23

24

25

26

27

28

29

30

31 


\section{Captions}

Figure 1. SEM image for (a) copper oxide NWs longer than $5 \mu \mathrm{m}$ with a diameter of 100-200 $\mathrm{nm}$, and (b) cobalt oxide NPs having mainly 100-200 nm in particle size.

Figure 21. (a) XRD analysis of copper oxide nanowires (NWs) scraped off from the copper foil, showing two types of copper oxide NWs consisting of $\mathrm{CuO}$ and $\mathrm{Cu}_{2} \mathrm{O}-\mathrm{Cu} 2 \mathrm{O}$ phase (* mark), and (b) XRD analysis of cobalt oxide nanoparticles (NPs) exhibiting the crystal structure of $\mathrm{Co}_{3} \mathrm{O}_{4}$.

Figure 3. (a) Image of a $\mathrm{CuO}$ nanowire by TEM analysis where an inset image is a magnified crystal structure of $\mathrm{CuO}$ for a red-lined square area (a black scale bar $=2 \mathrm{~nm}$ ), and (b) FFT patterns obtained from all area of the nanowire in Figure 3(a).

12 Figure 4. EDX analysis made with observation of a cross-sectional SEM image (tilt angle: $90^{\circ}$ ) of as-prepared copper oxide $\mathrm{NWs}$ layer shows two phases $\left(\mathrm{CuO}\right.$, and $\left.\mathrm{Cu}_{2} \mathrm{O}\right)$ of copper oxide depending on the position (a: nanowire at $2 \mu \mathrm{m}$ from the nanowire bottom surface, b: $1.5 \mu \mathrm{m}$ underneath the nanowire bottom surface, and c: $8 \mu \mathrm{m}$ underneath the nanowire bottom surface). The small peaks at 0.2-0.4 keV come from a carbon tape for sampling.

Figure 2. SEM images observed for (a) copper oxide NWs longer than $5 \mu \mathrm{m}$ with a diameter of $100-200 \mathrm{~nm}$, and (b) cobalt oxide NPs having mainly $100-200 \mathrm{~nm}$ in particle size.

Figure 53. Schematic illustration of the tandem-structured spectrally selective coating (SSC) layer concepts including coating cobalt oxide NPs into vertically aligned copper oxide NWs as well as transferring of copper oxide NW layer onto the layer of cobalt oxide NPs.

Figure 6Figure-4. (a) Comparison of the optical reflectance and FOM between the tandem SSC layer by spray-coating, and the SSC layer of copper oxide NWs only, or the SSC layer of cobalt oxide NPs only, and (b) SEM image of tandem SSC layer made by spray-coating of cobalt oxide 25 NPs onto vertical copper oxide NWs.

26 Figure 75. (a) Comparison of optical reflectance and FOM among different SSC layers, (b) a top view surface image of tandem SSC layer made by 10 min dip-coating in $18 \mathrm{wt} \%$ cobalt oxide solution without using a vacuum process, (c-1) a top view surface image and (c-2) a tilted surface image of tandem SSC layer made by dip-coating with 1 cycle of vac./venting in $18 \mathrm{wt} \%$ cobalt oxide solution, and (d-1) a top view surface image and (d-2) a tilted surface image of tandem SSC layer made by dip-coating with 1 cycle of vac./venting in $6 \mathrm{wt} \%$ cobalt oxide

32 solution. 
1 Figure 86. SEM images showing (a) a top view surface image and (b) a tilted surface of tandem

2 SSC layer made by dip-coating with 3 cycles of vac./venting procedures in $6 \mathrm{wt} \%$ cobalt oxide 3 solution.

4 Figure 97. Optical reflectance measured and FOM values calculated for tandem SSC layer 5 fabricated by dip-coating with 1 cycle of vac./venting process and 3 cycles of vac./venting 6 process in $6 \mathrm{wt} \%$ cobalt oxide solution.

7 Figure 108. SEM images representing (a) a stand-alone copper oxide NWs layer obtained by 8 etching $\mathrm{Cu}$ metal layer, and (b) a transferred copper oxide NWs layer attached onto cobalt oxide 9 layer with a thin binder resin layer.

10 Figure 119. Optical reflectance and FOM compared among structured SSC layers including a 11 copper oxide NWs layer only, a cobalt oxide NPs layer only, a spray-coated tandem SSC layer, a 12 dip-coated tandem SSC with 1 cycle of vac./venting process in $6 \mathrm{wt} \%$ cobalt solution, and a 13 transferred tandem SSC layer.

14 Table 1. Calculated FOM values from reflectance measurement of SSC layers.

15 16 17 18 19 20 21 22 23 24 25 26 27 28 29 30 

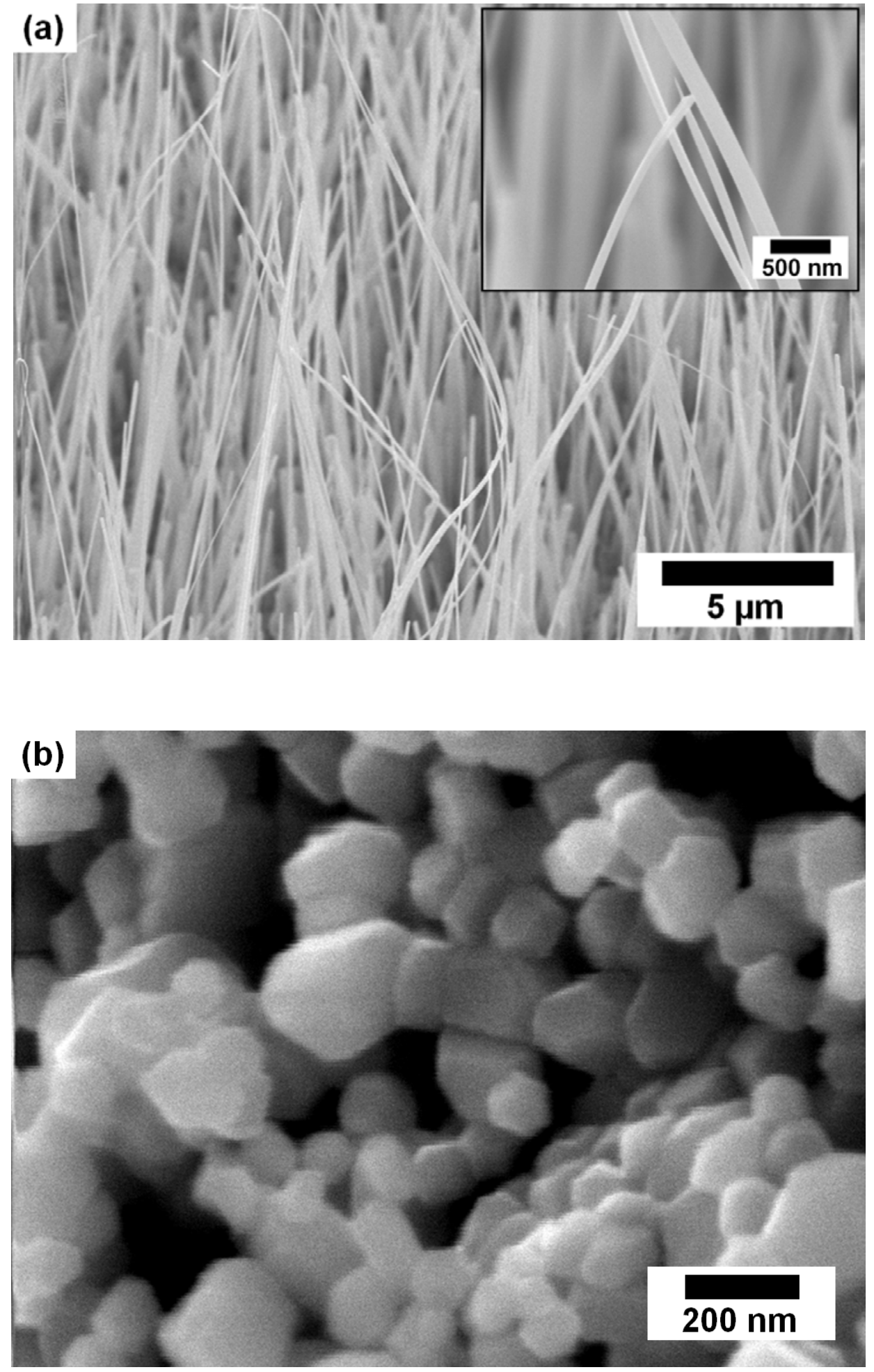

5 Figure 1. SEM images observed for (a) copper oxide NWs longer than $5 \mu \mathrm{m}$ with a diameter of $6 \quad 100-200 \mathrm{~nm}$, and (b) cobalt oxide NPs having mainly 100-200 $\mathrm{nm}$ in particle size. 
(a)

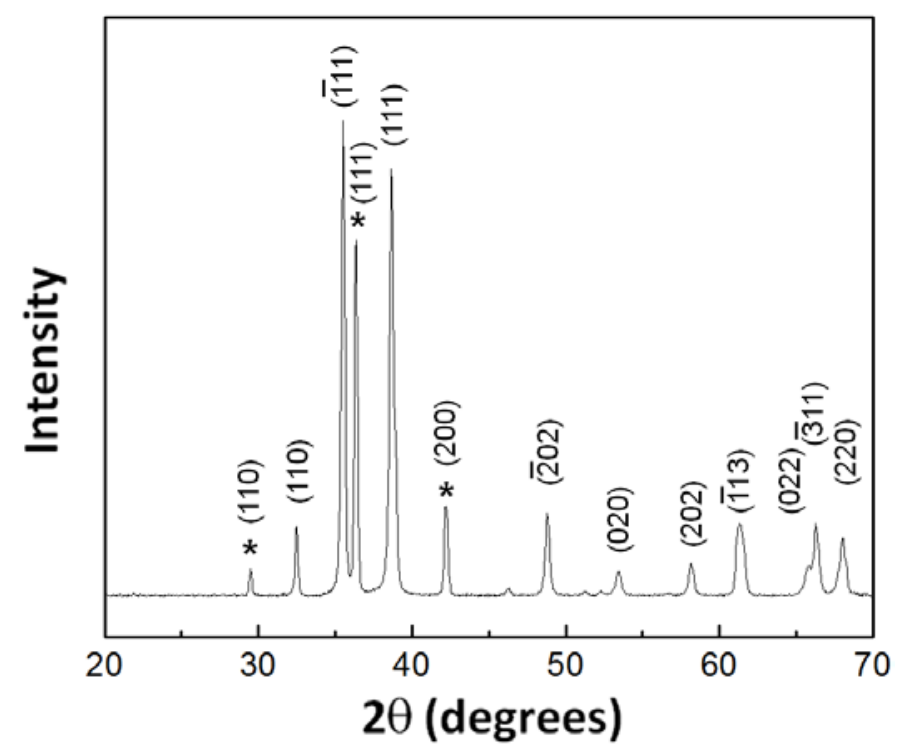

3

(b)

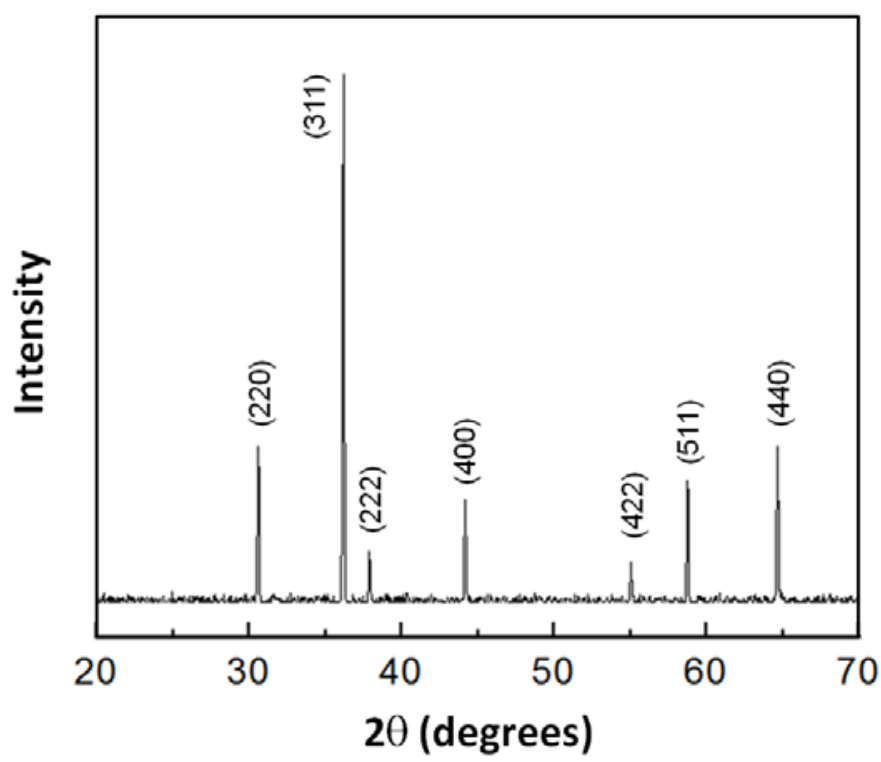

4

Figure 21. (a) XRD analysis of copper oxide nanowires (NWs) scraped off from the copper foil, 6 showing two types of copper oxide $\mathrm{NWs}$ consisting of $\mathrm{CuO}$ and $\mathrm{Cu}_{2} \mathrm{O} \mathrm{Cu} 2 \mathrm{O}$ phase (* mark), 7 and (b) XRD analysis of cobalt oxide nanoparticles (NPs) exhibiting the crystal structure of $8 \mathrm{Co}_{3} \mathrm{O}_{4}$. 

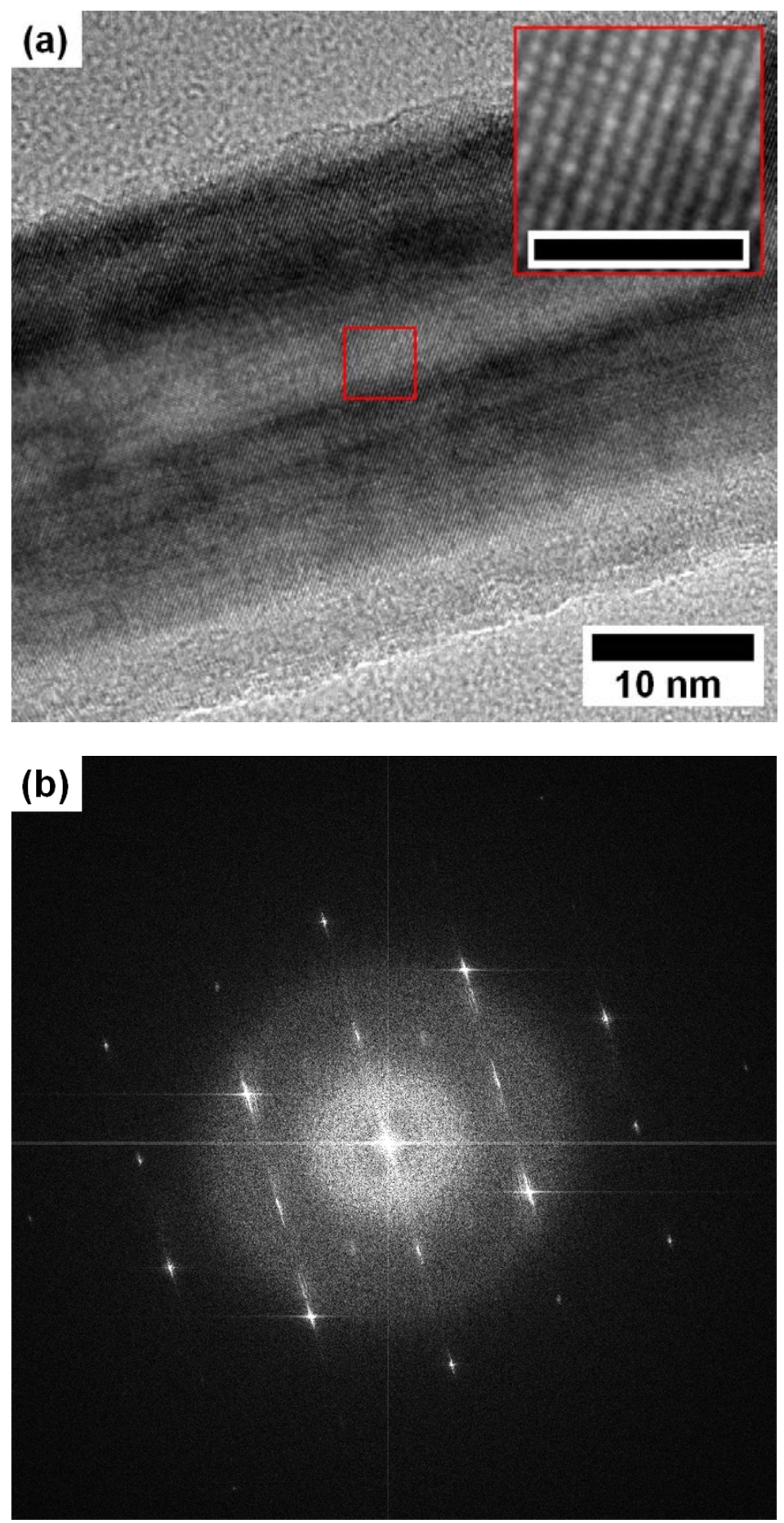

3 Figure 3. (a) Images of a single $\mathrm{CuO}$ nanowire by TEM analysis where an inset image is a

4 magnified crystal structure of $\mathrm{CuO}$ for a red-lined square area (a black scale bar $=2 \mathrm{~nm}$ ), and (b)

$5 \quad$ FFT patterns obtained from all area of the nanowire in Figure 3(a). 


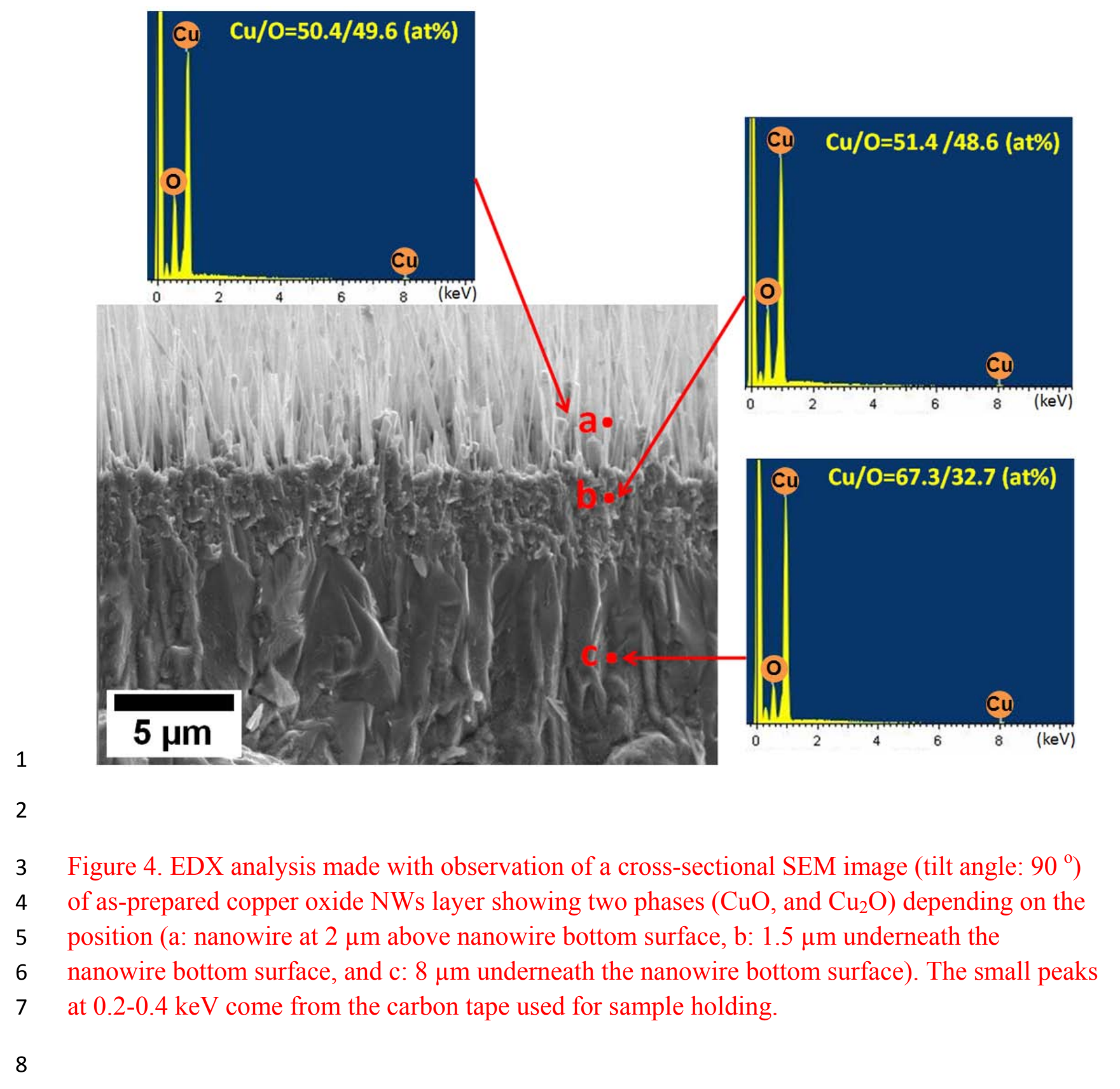




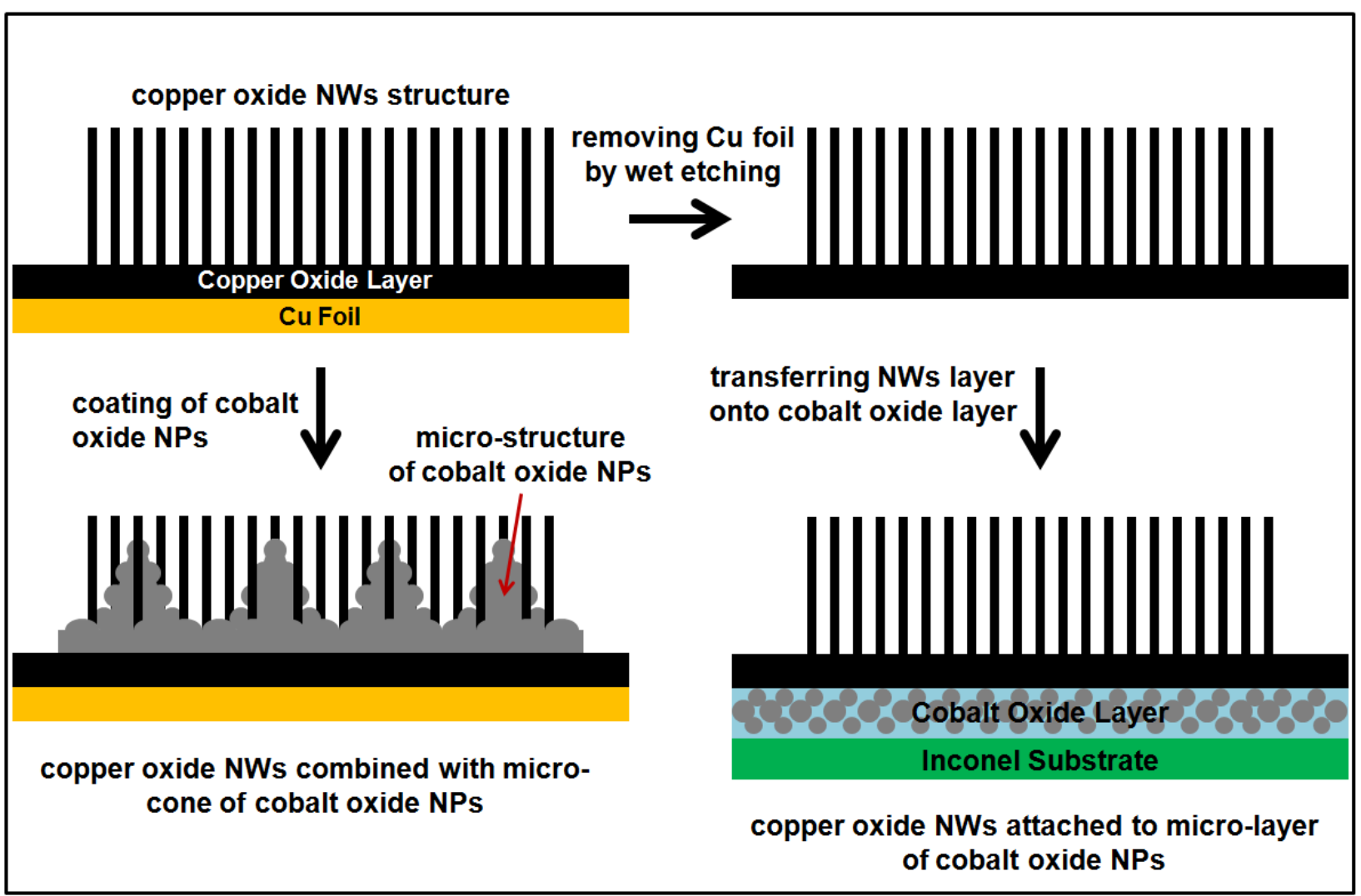

Figure 53. Schematic illustration of the tandem-structured spectrally selective coating (SSC) layer concepts including coating cobalt oxide NPs into vertically aligned copper oxide NWs as well as transferring of copper oxide NW layer onto the layer of cobalt oxide NPs. 

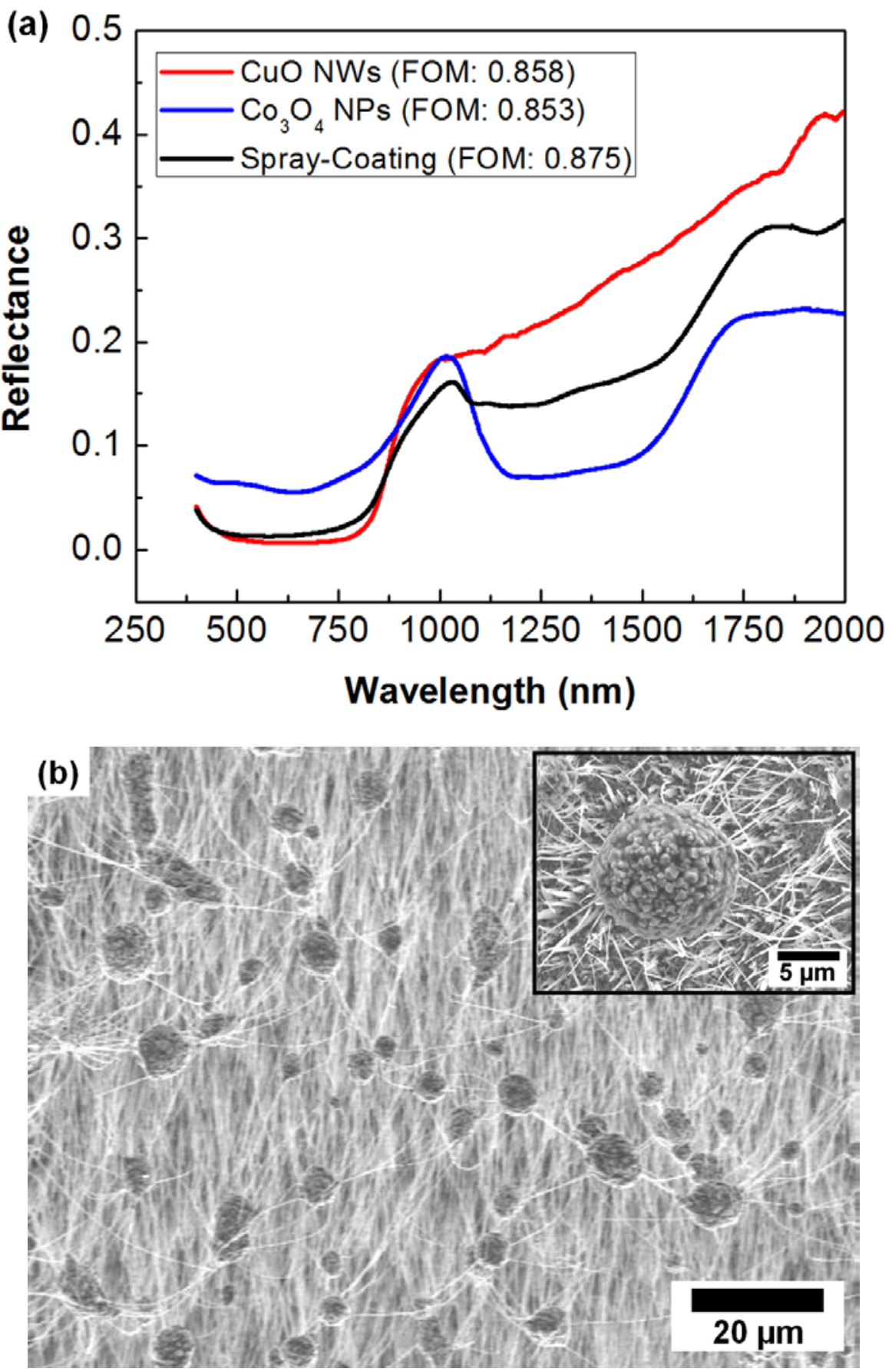

4 Figure 6Figure 4. (a) Comparison of the optical reflectance and FOM between the tandem SSC 5 layer by spray-coating, and the SSC layer of copper oxide NWs only, or the SSC layer of cobalt 6 oxide NPs only, and (b) SEM image of tandem SSC layer made by spray-coating of cobalt oxide 7 NPs onto vertical copper oxide NWs. 

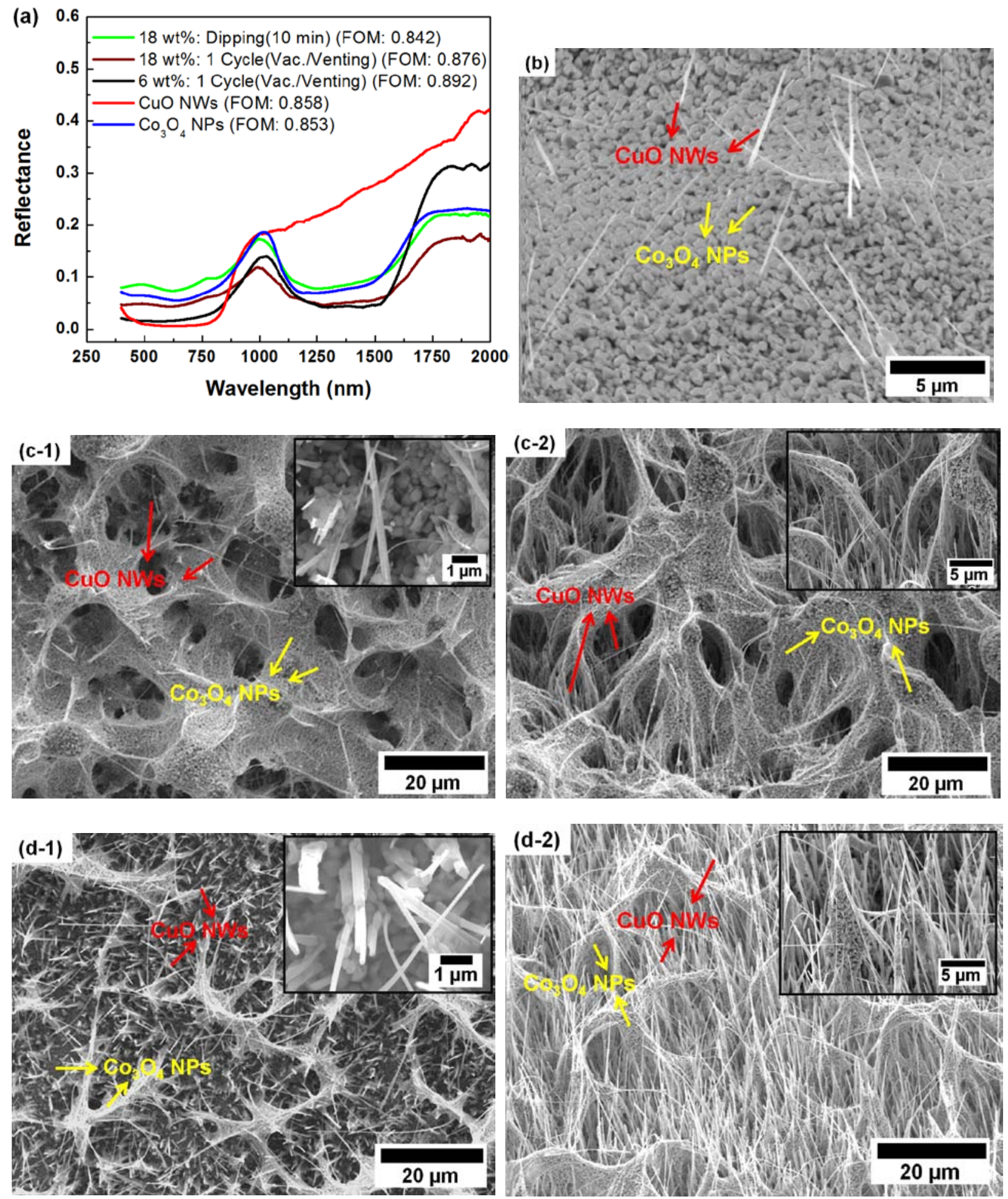

Figure 75. (a) Comparison of optical reflectance and FOM among different SSC layers, (b) a top

5 view surface image of tandem SSC layer made by 10 min dip-coating in $18 \mathrm{wt} \%$ cobalt oxide

6 solution without using a vacuum process, (c-1) a top view surface image and (c-2) a tilted

7 surface image of tandem SSC layer made by dip-coating with 1 cycle of vac./venting in $18 \mathrm{wt} \%$ 
1 cobalt oxide solution, and (d-1) a top view surface image and (d-2) a tilted surface image of

2 tandem SSC layer made by dip-coating with 1 cycle of vac./venting in $6 \mathrm{wt} \%$ cobalt oxide

3 solution.

4

5

6

7

8

9

10

11

12

13

14

15

16

17

18

19

20 

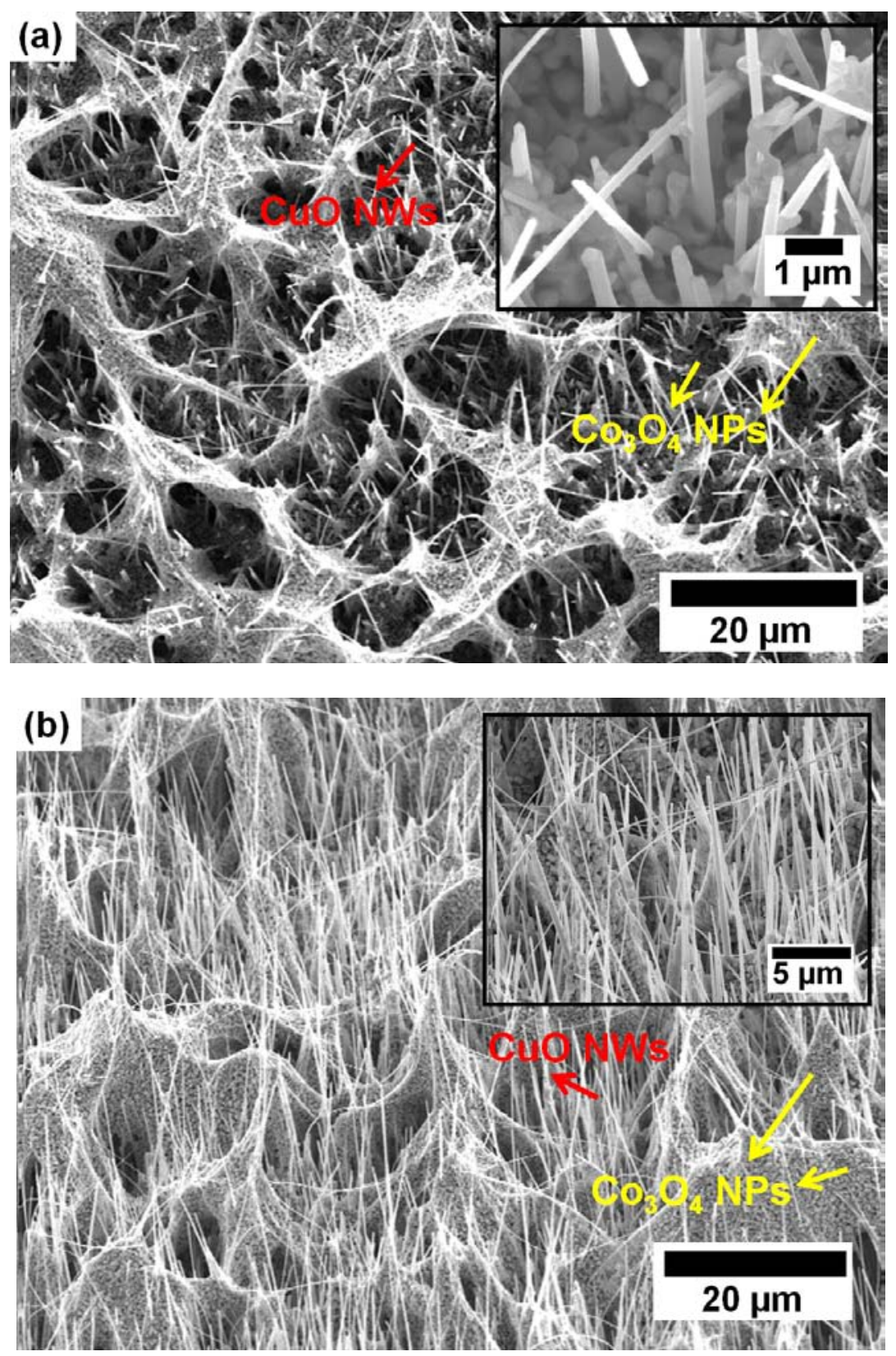

4 Figure 86. SEM images showing (a) a top view surface image and (b) a tilted surface of tandem 5 SSC layer made by dip-coating with 3 cycles of vac./venting procedures in $6 \mathrm{wt} \%$ cobalt oxide 6 solution. 


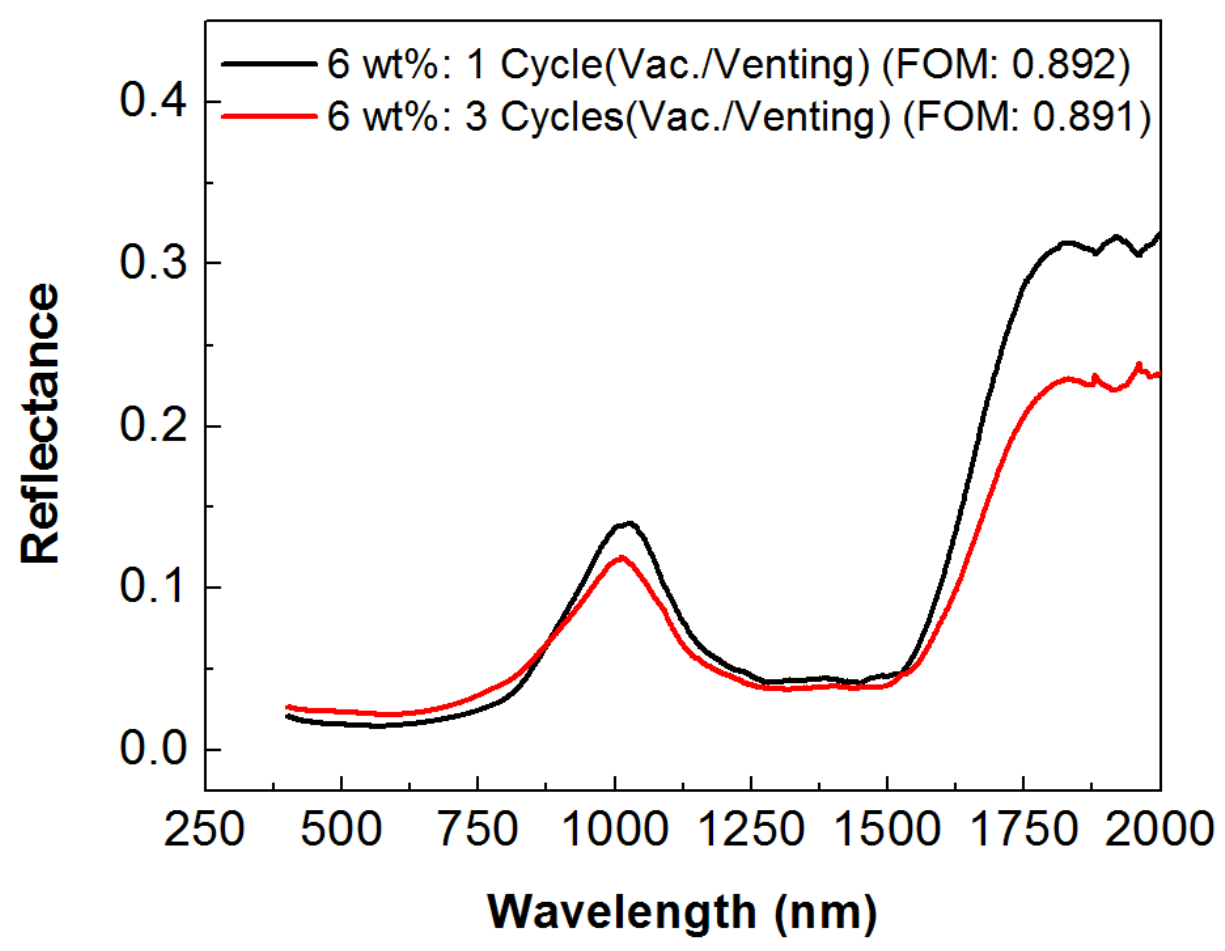

2

3 Figure 97. Optical reflectance measured and FOM values calculated for tandem SSC layer 4 fabricated by dip-coating with 1 cycle of vac./venting process and 3 cycles of vac./venting 5 process in $6 \mathrm{wt} \%$ cobalt oxide solution.

6

7

8

9

10

11

12

13

14

15 

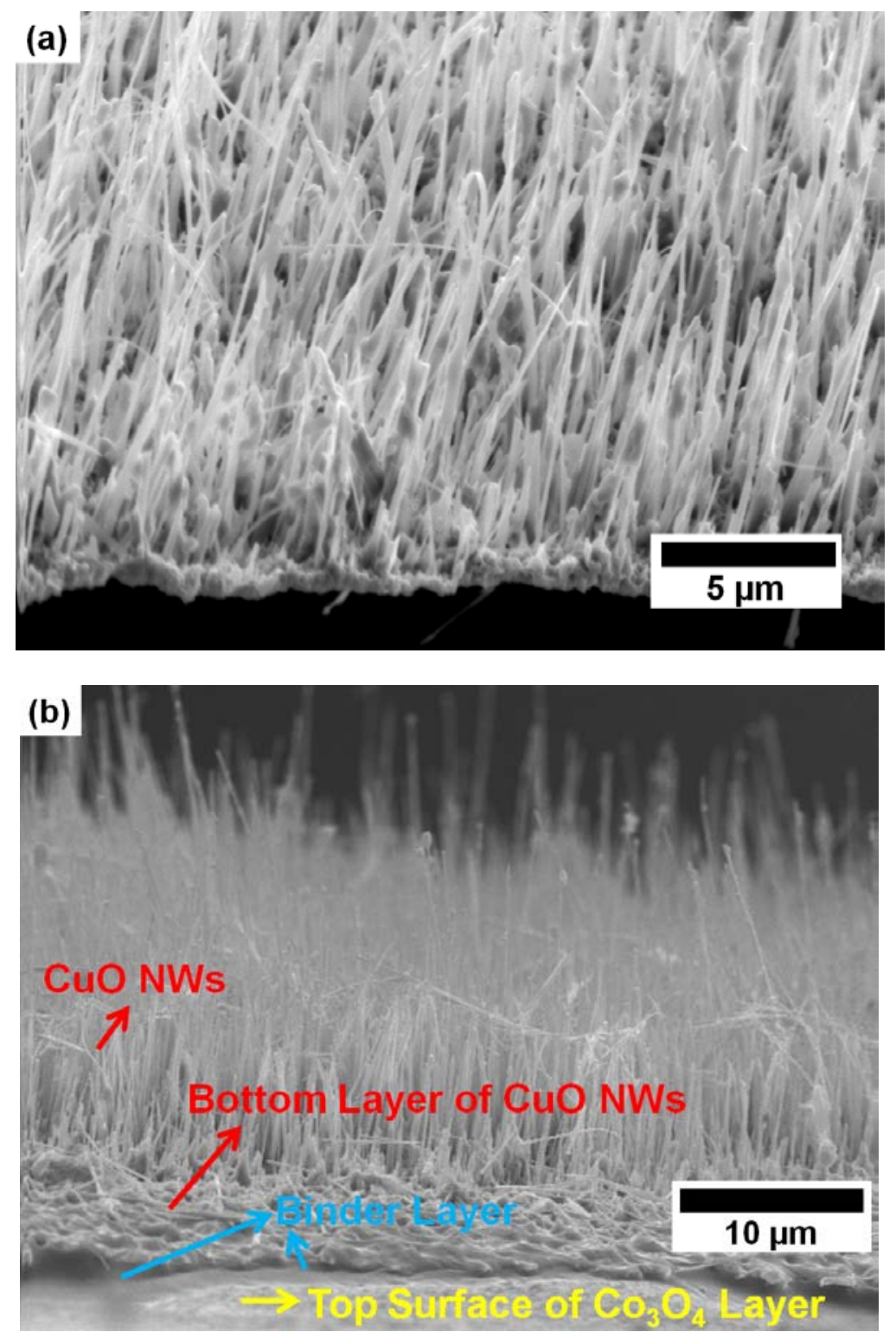

3 Figure 108. SEM images representing (a) a stand-alone copper oxide NWs layer obtained by

4 etching $\mathrm{Cu}$ metal layer, and (b) a transferred copper oxide NWs layer attached onto cobalt oxide 5 layer with a thin binder resin layer. 


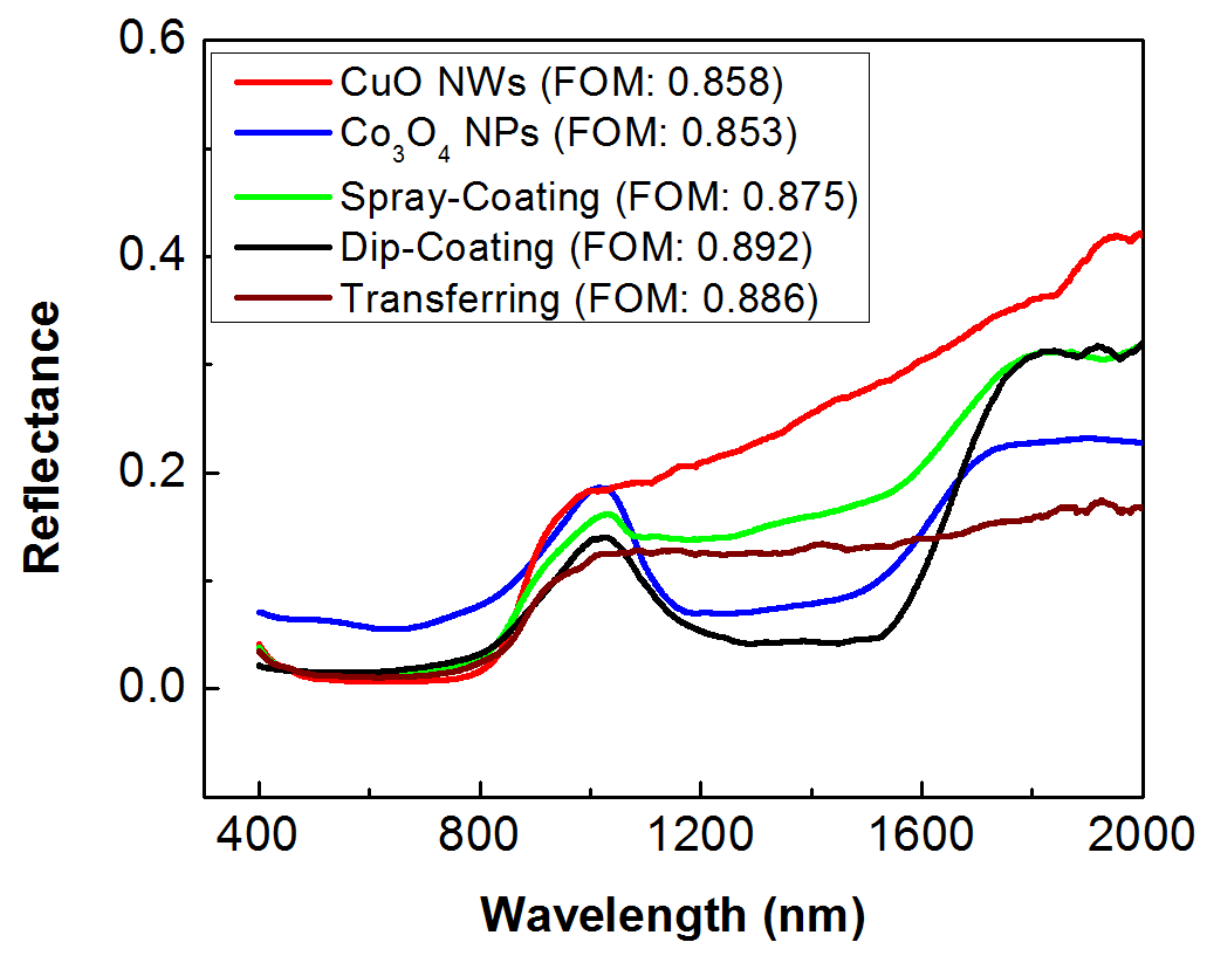

2 Figure 119. Optical reflectance and FOM compared among structured SSC layers including a

3 copper oxide NWs layer only, a cobalt oxide NPs layer only, a spray-coated tandem SSC layer, a

4 dip-coated tandem SSC with 1 cycle of vac./venting process in $6 \mathrm{wt} \%$ cobalt solution, and a

5 transferred tandem SSC layer.

6 
1 Table 1. Calculated FOM values from reflectance measurement of SSC layers.

2 SSC Layers

FOM

3 Copper Oxide NWs only

0.858

$4 \quad \mathrm{Co}_{3} \mathrm{O}_{4}$ NPs only

0.853

5 Tandem SSC by Spray-Coating

0.875

Tandem SSC by Dip-Coating (1 cycle, 6 wt\%)

0.892

$7 \quad$ Tandem SSC by Transferring

0.886

8

9

10

11

12

13

14

15

16

17

18

19

20

21

22

23

24

25

26

27

28

29 


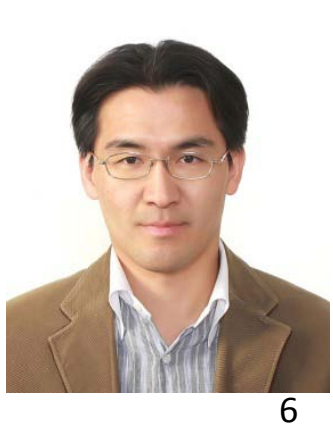

Tae $\mathrm{K}$ young $\mathrm{K}$ im is a $\mathrm{P}$ h.D. candidate in the Mat erials $\mathrm{S}$ cience and Engineering Program at University of California, S an Diego (UCSD). He obtained B.S. and M.S. degree from Yonsei University (South Korea) and had w orked at S amsung Cheil Inc. (presently, S amsung S DI) as a senior researcher mainly in the field of materials for renewable energy generation and storage systems. And then he has been studying and researching in UCSD since 2011.

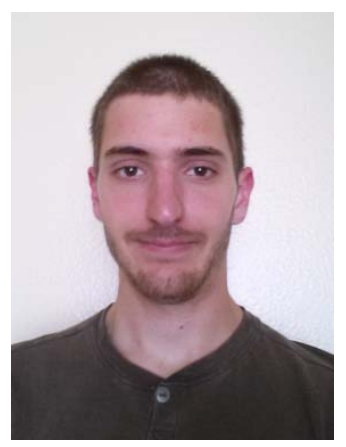

Bryan VanSaders is a Ph.D. graduate student in the Material Science and Engineering Program at University of California, San Diego (UCSD). He obtained hi s B .S. de gree from R utgers U niversity and M .S. de gree from UCSD. H e ha s f ocused on na no-scale opt ics, plasmonics, and optical metamaterials.

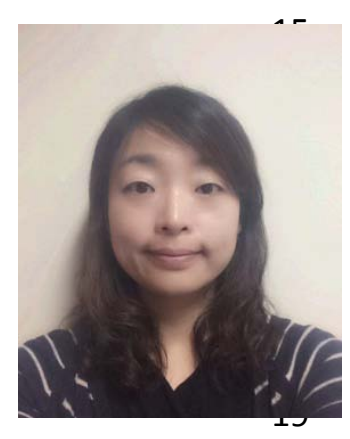

Jaeyun $\mathrm{M}$ oon is a $\mathrm{n}$ Assistant $\mathrm{P}$ rofessor of Mechanical E ngineering a $\mathrm{t}$ University of $\mathrm{N}$ evada at L as $\mathrm{V}$ egas ( UNLV). S he r eceived her Ph.D. degree in the Materials Science and Engineering Program from University of California, San Diego (UCSD). She obtained her B.S. and M.S. degree from Hanyang University (South Korea) and then had worked at Samsung Electronics as a senior engineer until 2009. Her research interest is renewable energy generations, especially the development and improvement of thermal energy conversion technologies such as 
1 concentrated solar pow er and thermoelecrics, us ing materials de sign and electrical/thermal 2 characterization techniques.

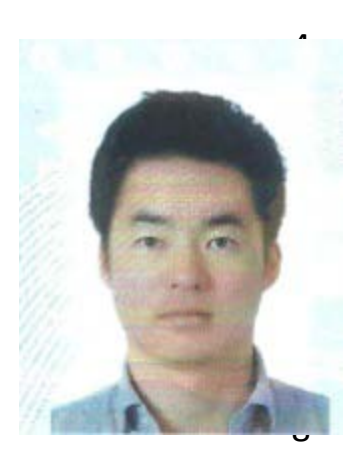

Taewoo Kim is a gradua te st udent in the Materials Science and Engineering Program at the University of California, San Diego (UCSD). He obtained B.S. degree in Chemistry Department from Korea Mi litary Academy (South K orea) a nd ha d worked a t Korea a rmy as a company commander. A nd then he ha s b een s tudying and $r$ esearching in UCSD since 2013. His research interest is to develop nanoparticles and 3-dimensional porous structure.

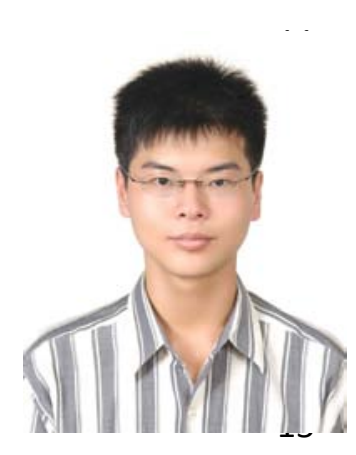

Chin-Hung Liu is a $\mathrm{P}$ h.D. candi date $\mathrm{i} \mathrm{n}$ the Mat erials $\mathrm{S}$ cience and Engineering Program at University of California, S an Diego (UCSD). He obtained B .S. de gree f rom $\mathrm{N}$ ational $\mathrm{C}$ heng $\mathrm{K}$ ung $\mathrm{U}$ niversity ( Taiwan, R.O.C.) a nd M .S. de gree from $\mathrm{N}$ ational T sing Hua U niversity (Taiwan, R.O.C.). He mainly focuses on solar cells, In-As III-V semiconductors and Nd-Fe-B permanent magnets. He has been studying and researching at UCSD since 2011. 


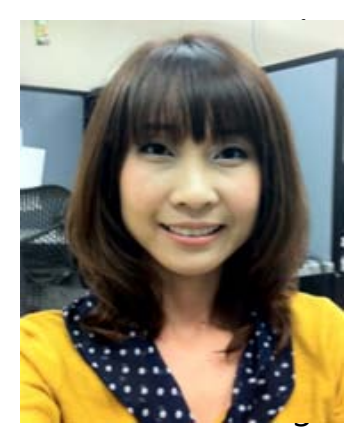

Jirapon K hamwannah received he r B .S. de gree ( 2006) i n M aterials Engineering f rom $\mathrm{K}$ ing $\mathrm{M}$ ongkut's $\mathrm{U}$ niversity of $\mathrm{T}$ echnology $\mathrm{T}$ honburi, Thailand. S he i s c urrently P h.D. candidate in $\mathrm{M}$ aterials $\mathrm{S}$ cience a nd Engineering Program at University of California, San Diego. Her research mainly focuses on advanced nanostructure materials and 3-D structure for applications in Dye-sensitized solar cells.

7

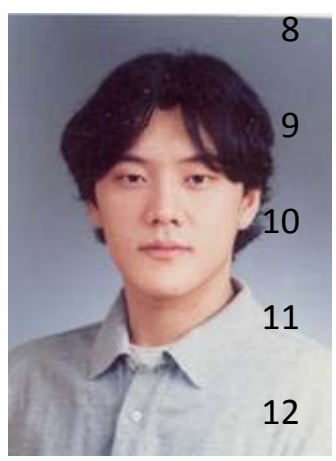

Dongwon Chun is a Ph.D. student in the Materials Science and Engineering Program at University of California, San Diego (UCSD) since 2012. He obtained B.S. and M.S. degree from Yonsei University (South Korea) and had worked at the Korea Institute of Science and Technology as a research scientist mainly working on the Bio-MEMs and Materials

13 Analysis.

14

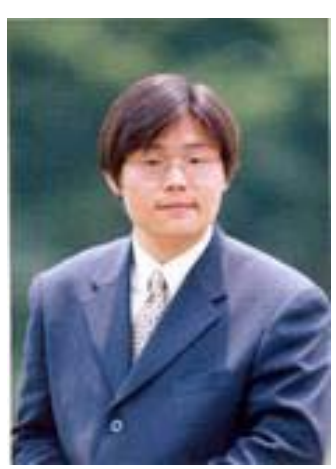

Duyoung $\mathrm{C}$ hoi is a $\mathrm{P}$ h.D. candidate in the Mat erials $\mathrm{S}$ cience and Engineering Program at the University of California, S an Diego (UCSD). He obtained B.S. and M.S. degree from Inha University (South Korea). He has been studying and researching on graphene and transition metal oxide composite for renewable energy generation and storage systems in UCSD

since 2009. 


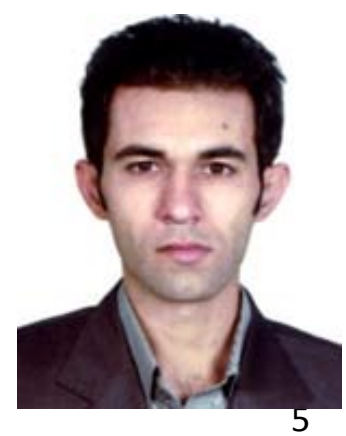

Alireza $\mathrm{K}$ argar i s a $\mathrm{P}$ h.D. candidate in $\mathrm{t}$ he $\mathrm{E}$ lectrical and Computer Engineering D epartment of the U niversity of C alifornia, San D iego. He received B .S. de gree from S hiraz U niversity in Shiraz, I ran. H is c urrent research interests are design and fabrication of different nanostructures for solar e nergy $\mathrm{c}$ onversion de vices $\mathrm{w}$ ith $\mathrm{f}$ ocus on $\mathrm{s}$ olar $\mathrm{f}$ uel ge neration systems.

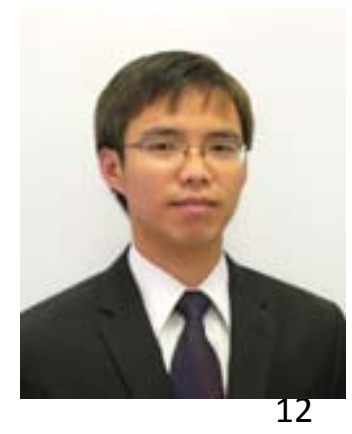

Renkun Chen received his B.S. degree in Thermo-physics from Tsinghua University in 2004, a nd a Ph.D. de gree in M echanical Engineering from University of California, Berkeley in 2008. Following a one-year stint as a postdoctoral fellow at Lawrence B erkeley National Laboratory, he joined University of $\mathrm{C}$ alifornia, San Diego as an Assistant $\mathrm{P}$ rofessor i $\mathrm{nt}$ he Department of Mechanical and Aerospace Engineering in 2009. His research interests include nanoscale heat transfer, energy conversion materials, and thermal management.

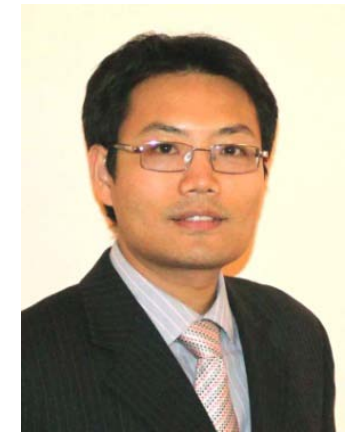

Zhaowei L iu is an Assistant P rofessor of Electrical and Computer Engineering at Univesity of California, San diego (UCSD). He received his Ph.D. i $n$ mechanical e ngineering ( MEMS/Nanotechnology) f rom University of C alifornia, L os A ngeles in 2006 . B efore $\mathrm{j}$ oining U CSD faculty, he was a post-doctoral researcher at the NSF Nanoscale Science \& 
1 Engineering $\mathrm{C}$ enter ( NSEC) i $\mathrm{n}$ the Mech anical E ngineering Department at U niversity of

2 California, Berkeley. His re search interest includes nanophotonics, plasmonics, metamaterials, 3 energy and ultrafast opto-electronics.

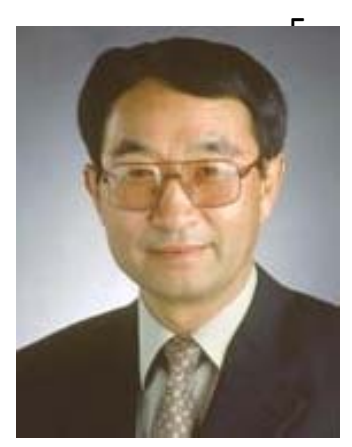

Sungho J in received his B.S de gree in Metallurgical E ngineering from Seoul National University in 1969, and Ph.D. degree in Materials Science \& Engineering from University of California, Berkeley in 1974. A fter 26 years of R\&D at Bell Laboratories at Murray Hill, New Jersey, he joined University of Californai, S an D iego (UCSD) in 2002 a s a P rofessor and 10 Iwama Endowed Chair. He is currently a Distinguished Professor at UCSD, and is serving as the

11 Director of U CSD-wide Mat erials S cience \& E ngineering Program. $\mathrm{H}$ is $\mathrm{r}$ esearch interests 12 include R\&D of na no materials, magnetic materials, electronic materials, energy materials, and 13 bio materials. 